\title{
Incidence and Survival Trends of Pancreatic Cancer in Girona: Impact of the Change in Patient Care in the Last 25 Years
}

\author{
Adelaida García-Velasco ${ }^{1,2, *}$, Lluís Zacarías-Pons ${ }^{3}$, Helena Teixidor ${ }^{3}$, Marc Valeros ${ }^{3}$,

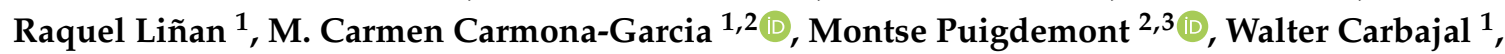 \\ Raquel Guardeño ${ }^{1}$, Núria Malats ${ }^{4}{ }^{\mathbb{D}}$, Eric Duell ${ }^{5}$ and Rafael Marcos-Gragera ${ }^{2,3,6}$ \\ 1 Medical Oncology Department, Josep Trueta Universitary Hospital, Catalan Institute of Oncology, \\ Av de França, 17007 Girona, Spain; rlinan@iconcologia.net (R.L.); ccarmona@iconcologia.net (M.C.C.-G.); \\ wcarbajal@iconcologia.net (W.C.); rguardeno@iconcologia.net (R.G.) \\ 2 Descriptive Epidemiology, Genetics and Cancer Prevention Group, Biomedical Research Institute (IDIBGI), \\ C/Dr. Castany, s/n, 17190 Salt, Spain; mpuigdemont@iconcologia.net (M.P.); \\ rmarcos@iconcologia.net (R.M.-G.) \\ 3 Epidemiology Unit and Girona Cancer Registry, Oncology Coordination Plan, Department of Health, \\ Autonomous Government of Catalonia, Catalan Institute of Oncology, Av. França, s/n, 17004 Girona, Spain; \\ lzacarias@idibgi.org (L.Z.-P.); helenateixipuig@gmail.com (H.T.); marcvaleros97@gmail.com (M.V.) \\ 4 Genetic and Molecular Epidemiology Group, Spanish National Cancer Research (CNIO) and CIBERONC, \\ 28029 Madrid, Spain; nmalats@cnio.es \\ 5 Unit of Biomarkers and Susceptibility, Oncology Data Analytics Program, Catalan Institute of Oncology (ICO), \\ Colorectal Cancer Group, ONCOBELL Program, Bellvitge Biomedical Research Institute (IDIBELL), \\ L'Hospitalet de Llobregat, Consortium for Biomedical Research in Epidemiology and Public Health (CIBERESP), \\ 08908 Barcelona, Spain; eduell@iconcologia.net \\ 6 Consortium for Biomedical Research in Epidemiology and Public Health \\ (CIBER Epidemiología y Salud Pública, CIBERESP), 28029 Madrid, Spain \\ * Correspondence: agvelasco@iconcologia.net
}

Received: 30 November 2020; Accepted: 16 December 2020; Published: 19 December 2020

check for updates

\begin{abstract}
Background: We investigated the incidence and survival trends for pancreatic cancer (PC) over the last 25 years in the Girona region, Catalonia, Spain; (2) Methods: Data were extracted from the population-based Girona Cancer Registry. Incident PC cases during 1994-2015 were classified using the International Classification of Diseases for Oncology Third Edition (ICD-O-3). Incidence rates age-adjusted to the European standard population $\left(\mathrm{ASR}_{\mathrm{E}}\right)$ and world standard population $\left(\mathrm{ASR}_{\mathrm{W}}\right)$ were obtained. Trends were assessed using the estimated annual percentage of change (EAPC) of the ASR $\mathrm{E}_{13}$. Observed and relative survivals (RS) were estimated with the Kaplan-Meier and Pohar Perme methods, respectively; (3) Results: We identified 1602 PC incident cases. According to histology, $44.4 \%$ of cases were exocrine PC, $4.1 \%$ neuroendocrine, and 51.1\% malignant-non-specified. The crude incidence rate (CR) for PC was 11.43 cases-per-100,000 inhabitants/year. A significant increase of incidence with age and over the study period was observed. PC overall 5-year RS was $7.05 \%$ (95\% confidence interval (CI) 5.63; 8.84). Longer overall survival was observed in patients with neuroendocrine tumours (5-year RS 61.45\%; 95\% CI 47.47; 79.55). Trends in 5-year RS for the whole cohort rose from 3.27\% (95\% CI 1.69-6.35) in 1994-1998 to 13.1\% (95\% CI 9.98; 17.2) in 2010-2015; (4) Conclusions: Incidence rates of PC in Girona have increased in the last two decades. There is a moderate but encouraging increase in survival thorough the study period. These results can be used as baseline for future research.
\end{abstract}

Keywords: pancreatic cancer; incidence; relative survival; pancreatic neuroendocrine tumours 


\section{Introduction}

Pancreatic cancer (PC) is a major health problem in developed countries due to its high mortality rate and its increasing incidence [1]. It used to be an uncommon neoplasm in the European Union (EU) but now it ranks as the 7th most common form of cancer, representing 3.0\% of all new cancer cases [2]. Cancer incidence projections of GLOBOCAN (Global Cancer Observatory) 2018 point out that the number of new cases will rise in the whole EU ( $+32 \%)$ by 2040 , and up to $+46 \%$ in Spain [3]. It is already the fourth leading cause of cancer death in Western countries, the 3rd in Spain [4], and in the next 20 years its impact is expected to increase up to being the second leading cause of cancer death and the main cause of lost years of quality-adjusted life (QALYs) [5].

More than $90 \%$ of malignant tumors of the pancreas arise from the exocrine pancreas, with pancreatic ductal adenocarcinoma representing $85 \%$ of cases [6]. Its prognosis is ominous, with overall survival rates under $20 \%$ one year after diagnosis and $<10 \%$ at 5 years [7-10]. This has been attributed, among other causes, to the premature vascular, lymphatic and perineural spread of these tumors, which makes that most of the patients present disseminated disease at diagnosis [11]. Improvements in diagnostic tools and systemic treatments have been achieved in the last two decades benefitting a small proportion of patients and, therefore, with only minimal impact on mortality. In this context, PC represents a major challenge for cancer research and has fostered growing interest by clinicians and epidemiologists.

PC etiology is still not well known. Established risk factors are smoking, high alcohol consumption, diabetes mellitus, obesity, chronic pancreatitis, mucinous intra-ductal neoplasia (IPMN), familial aggregation of PC and some hereditary syndromes (i.e., familial multifocal atypical melanoma, Peutz-Jeghers syndrome and hereditary breast and ovarian cancer associated with BRCA mutations) [6]. Furthermore, up to 40 low-penetrance genetic variants have been associated with sporadic PC risk based on GWAS (Genome-wide association study) in consortia of multiple PC studies. However, these factors do not fully explain the variation in risk for PC, and familial risk and genetic syndromes account for less than $10 \%$ of PC.

We conducted a population-based study of patients diagnosed with PC in Girona, a north-eastern province of Spain with one of the oldest population cancer registries in the country with regular data quality review, to analyze the incidence and survival trends for PC in the region.

\section{Materials and Methods}

\subsection{Data Source}

Data were extracted from the population-based Girona Cancer Registry (GCR) - in the northeast of Spain (covering a population of 739,607 inhabitants in 2015) - during 1994-2015. Cases were registered according to the International Agency for Research on Cancer (IARC) guidelines with a completeness of $96.3 \%$.

\subsection{Study Population}

The study included cases with PC (International Classification of Diseases for Oncology Third Edition (ICD-O-3) histological codes: 8000, 8010, 8020, 8041, 8070, 8140, 8150, 8151, 8153, 8240, 8246, $8249,8260,8452,8453,8470,8480,8481,8490,8500,8510,8550,8560$ and 8971; topography C25) [12]. We excluded patients with tumors in situ and histologically verified stromal tumors, lymphomas and sarcomas ( $n=3$ cases). Also, patients aged less than 15 years old at the date of PC diagnosis were excluded. All cases were retrospectively revised individually. Tumors were categorized by histological subtypes following the 4th edition of World Health Organisation (WHO) classification of tumors of the digestive system [13], to ensure comparability. For the analysis, two main histological subgroups were considered: pancreatic neuroendocrine tumours (PNET) and non-neuroendocrine PC (non-PNET), besides, a third subgroup (non-HC PC) includes all cases without microscopic verification 
(Supplementary Table S1). The study population was further stratified by sex and grouped by age at diagnosis into five categories: (15-44 y), (45-54 y), (55-64 y) and elderly persons (65-74 y and $\geq 75 \mathrm{y}$ ).

The primary site was defined following the ICD-O-3 codes C25.0-C25.9: Head of pancreas, (C25.0), body of pancreas (C25.1), tail of pancreas (C25.2), pancreatic duct (C25.3), "others" including islets of Langerhans (C25.4), other specified parts of pancreas (C25.7), overlapping lesion of pancreas (C25.8) and pancreas, NOS (C25.9). Due to the low numbers of cases we jointly analysed the following codes: C25.3 (ducts), C25.4 (islets+), C25.7 (other parts) and C25.8 (overlapping). In the Girona Cancer registry, we collect retrospectively all NETs regardless of their behaviour (malign or uncertain) from 1994 until now. All these cases were recoded following the 2010 international recommendation for codifying NETs in cancer registries.

Survival analysis was performed on a dataset excluding cases identified by death certificate only (DCO) and those cases diagnosed at autopsy ( $n=119$ cases). Follow up was defined from data of diagnosis to date of last known vital status (death by any cause, date of loss of follow-up, or date of end of follow-up at 31st December 2018). Vital status of patients was obtained by linking records to the Catalan registry of Mortality and the National Death Index. We estimated 1- and 5-year observed survival (OS) by sex, age-group, histological type (survival was analyzed jointly for both non-PNETs and non-HC PC on the basis that they were more likely to be carcinomas), tumour location and period of diagnosis. We did not calculate survival estimates when subgroups had $<20$ patients available for analysis.

\subsection{Study Outcomes and Statistical Analysis}

For data analysis, version 3.4.3 of RStudio was used. Statistical significance was defined as two-sided $p<0.05$. The study focused in two main outcomes: incidence and survival. Incidence was analyzed in terms of crude rate (CR) and estimates were age-standardized with the following weights: world (ASRw), United States 2000 (ASRus2000), European 1976 (ASRE76) and European 2013 (ASRE13) standard populations. For the sake of simplicity, we will mainly refer to ASRE13 in the text. Trends were assessed using the estimated annual percentage of change (APC) of the ASRE13. The jointpoint loglinear regression version 4.5.0.1 model was used to calculate APC. To analyze differences between sexes according to clinical and pathological characteristics, we used the T test or Chi square test. Version 22.0.0 of SPSS and WebSurvCa [14] have been used for survival analysis. Observed survival was calculated using the Kaplan-Meier method. To eliminate the possibility of death from other causes, the relative survival was calculated using the Pohar-Perme estimator [15], which represents the hypothetical survival that patients would have had if their cancer had been the only possible cause of death. To calculate the net survival, we used life tables and general mortality with the Edlant-Johnson method [16].

\subsection{Ethics Approval}

This study involves a secondary data analysis from existing data and records. The information was recorded by the investigators in such a manner that subjects could not be identified, directly or through identifiers linked to the subjects. The participating cancer registry has data management policies in place allowing for the preservation of individual patients' confidentiality including the ethical approvals from local mandatory bodies. For this type of study, formal consent is not required.

\section{Results}

\subsection{Baseline Characteristics}

Table 1 shows the characteristics of the 1602 patients with PC identified in Girona during 1994-2015. Of them, $46 \%$ were women and $54 \%$ men. The mean age at diagnosis was 70.57 years (range 19-101), men were younger (68 years) than women (73 years), $p<0.001$. DCO-cases were $7.5 \%$ in men and $7.3 \%$ in women. Patients over 64 years old represented $70 \%$ of cases $(64.51 \%$ in males and $76.11 \%$ 
in females). Overall, $48.5 \%$ had a pathologically verified PC. Among them, non-PNETs accounted for $91.63 \%$ of cases and PNETs $8.37 \%$ (4.06\% of the whole series). Non-HC PC comprised the largest group of PC in our study $\left(51.5 \%, \mathrm{ASR}_{\mathrm{E} 13}=6.8\right.$ per 100,000 p-y). Within non-PNETs, the most frequent histology was Adenocarcinoma (Supplementary Table S1). Staging information was only available in 613 patients, $415(67.69 \%)$ were stage IV.

Table 1. Distribution of pancreatic tumours characteristics according to sex. Girona 1994-2015.

\begin{tabular}{|c|c|c|c|c|}
\hline & Total & Males & Females & $p$-Value \\
\hline & $n(\%)(\% *)$ & $n(\%)(\% *)$ & $n(\%)(\% *)$ & \\
\hline $\mathrm{AGE}^{\mathrm{AT}}$ DIAGNOSIS^^ & & & & $<0.001$ \\
\hline Mean & 70.57 & 68.49 & 73.01 & \\
\hline Median & 72 & 70 & 75 & \\
\hline Min-max & 19-101 & $28-96$ & 19-101 & \\
\hline AGE GROUP (YEARS) ${ }^{+}$ & & & & $<0.001$ \\
\hline $15-44$ & $52(3.25)$ & $29(3.35)$ & $23(3.12)$ & \\
\hline $45-54$ & $150(9.36)$ & 98 (11.33) & $52(7.06)$ & \\
\hline $55-64$ & 281 (17.54) & $180(20.81)$ & $101(13.7)$ & \\
\hline $65-74$ & $432(26.97)$ & $262(30.29)$ & $170(23.07)$ & \\
\hline $75+$ & $687(42.88)$ & $296(34.22)$ & $391(53.05)$ & \\
\hline BASIS OF DIAGNOSIS $^{+}$ & & & & $<0.001$ \\
\hline Death certificate only (DCO) & $119(7.43)$ & $65(7.51)$ & $54(7.33)$ & \\
\hline Clinical only & $4(0.25)$ & $1(0.12)$ & $3(0.41)$ & \\
\hline Clinical investigation & $642(40.07)$ & $304(35.14)$ & $338(45.86)$ & \\
\hline Cytology & $251(15.67)$ & $148(17.11)$ & $103(13.98)$ & \\
\hline Histology of a metastasis & $155(9.68)$ & $91(10.52)$ & $64(8.68)$ & \\
\hline Histology of a primary tumour & $412(25.72)$ & $246(28.44)$ & $166(22.52)$ & \\
\hline Unknown & $19(1.19)$ & $10(1.16)$ & $9(1.22)$ & \\
\hline TOPOGRAPHICAL SUB-SITE $^{+}$ & & & & 0.604 \\
\hline Head of the pancreas (C25.0) & $658(41.07)$ & $357(41.27)$ & $301(40.84)$ & \\
\hline Body of the pancreas (C25.1) & $109(6.8)$ & $56(6.47)$ & $53(7.19)$ & \\
\hline Tail of the pancreas (C25.2) & $89(5.55)$ & $51(5.89)$ & $38(5.15)$ & \\
\hline Other specified parts of the pancreas $(C 25.3,4,7,8)$ & $61(3.8)$ & $28(3.23)$ & $33(7.47)$ & \\
\hline Pancreas, NOS (C25.9) & $685(42.75)$ & $373(43.12)$ & $312(42.33)$ & \\
\hline HISTOLOGICAL GROUPS ${ }^{+}$ & & & & $<0.001$ \\
\hline PNETs & $65(4.06)$ & $37(4.28)$ & $28(3.8)$ & \\
\hline Pancreatic carcinomas (non-neuroendocrine) & $712(44.44)$ & $424(49.02)$ & $288(39.08)$ & \\
\hline Pancreatic tumours non-histologically confirmed & $825(51.5)$ & $404(46.71)$ & $421(57.12)$ & \\
\hline TNM STAGE $^{+}$ & & & & 0.556 \\
\hline I & $21(1.31)(3.42)$ & $10(1.15)(3.04)$ & $11(1.49)(3.84)$ & \\
\hline IIA & $37(2.31)(6.03)$ & $21(2.43)(6.40)$ & $16(2.17)(5.61)$ & \\
\hline IIB & $70(4.37)(11.41)$ & $41(4.74)(12.5)$ & $29(3.93)(10.17)$ & \\
\hline III & $70(4.37)(11.41)$ & $43(4.97)(13.1)$ & $27(3.66)(9.47)$ & \\
\hline IV & $415(25.90)(67.69)$ & $213(24.62)(64.93)$ & $202(27.41)(70.87)$ & \\
\hline Unknown & 989 (61.73) & $537(62.08)$ & $452(61.32)$ & \\
\hline PERIOD OF DIAGNOSIS ${ }^{+}$ & & & & 0.993 \\
\hline 1994-1998 & $239(14.91)$ & $128(14.79)$ & 111 (15.06) & \\
\hline 1999-2003 & 327 (20.41) & $177(20.46)$ & $150(20.35)$ & \\
\hline 2004-2009 & $453(28.27)$ & $246(28.43)$ & $207(28.08)$ & \\
\hline 2010-2015 & 583 (36.39) & $314(36.30)$ & 269 (36.49) & \\
\hline TOTAL & $1602(100.0)$ & $865(54.2)$ & $737(45.8)$ & \\
\hline
\end{tabular}

PNETs-Pancreatic neuroendocrine tumours. TNM-Tumor node metastasis. (\%) * Percentage with respect to the $n$ cases with confirmed stage ( $n=613$ for both sexes, $n=328$ for males, and $n=286$ for females).^ Results from $t$-test.

+ Results from Chi-Square test.

\subsection{Incidence and Incidence Temporal Trends}

The overall CR for the whole series was 11.43 cases per 100,000 inhabitants/year. Compared with females, males had higher incidence rates: 12.17 versus 10.34 , respectively. The overall ASR $\mathrm{E}_{\mathrm{E} 13}$ was 13.19 (95\% confidence interval (CI) $12.55 ; 13.85)$ and the $\mathrm{ASR}_{W}$ was $5.68(95 \%$ CI $5.38 ; 6.01)$ (Table 2). Age-specific rates reflected an increase with advancing age, having the Girona population over 85 years the highest rate (74.5 cases per 100,000 inhabitants/year) (Figure 1). During the study period, the ASR $\mathrm{E}_{13}$ 
gradually increased from 10.6 in 1994 to 14.21 in 2015, with a significant EAPC of 1.55\%. This increase was observed in both males (EAPC $=1.35 \%$ ) and females (EAPC $=1.67 \%)$. No differences in incidence rates between the geographical areas of Girona province have been found, and no significant cut-point was identified by joinpoint regression. (Supplementary Table S2; Figure 2a-c).

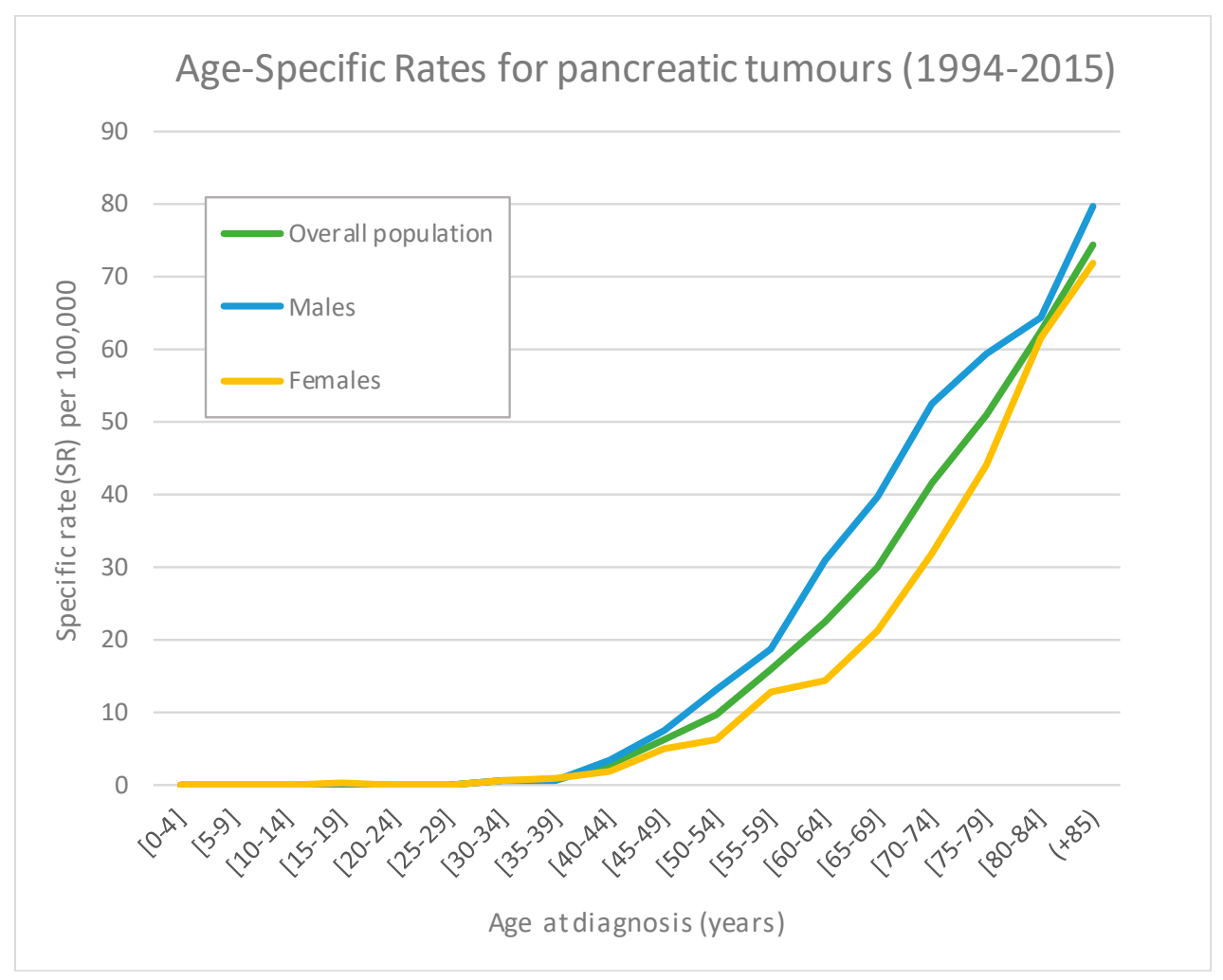

Figure 1. Age-specific incidence rates for pancreatic tumours of the overall population and according to sex.

Within the non-PNETs, the incidence trend evidences a gradual increase. Regarding the ASR, results show an $\mathrm{ASR}_{\mathrm{E} 13}$ of $5.87(95 \%$ CI $5.44 ; 6.32)$, that heightens with age (Table 2). During the study period, the ASR $\mathrm{E} 13_{3}$ increased with a significant EAPC of $6 \%$. No significant cut-point was identified by joinpoint regression in this subgroup (Figure 2d).

In our study, PNETs represent only $4.06 \%$ of the whole series. The CR was $0.5(95 \%$ CI $0.38 ; 0.63)$. As for the ASR, results show an $\mathrm{ASR}_{\mathrm{E} 13}$ of $0.53(95 \% \mathrm{CI} 0.41 ; 0.68)$ and an $\mathrm{ASR}_{\mathrm{W}}$ of $0.33(95 \% \mathrm{CI} 0.25 ; 0.45)$. Rates remain stable during 1994-2015 with a non-statistically significant EAPC of 3.16\% (Figure 2e).

The subgroup of non-HC PC represents $51.5 \%$ of all cases. A proportion that was higher in females than in males (57.12\% vs. 46.71\%). Incidence analyses reveal a total $\mathrm{ASR}_{\mathrm{E} 13}$ of 6.83 (95\% CI 6.37; 7.32) that hikes up to 45.9 (95\% CI 41.9; 50.1) in >75-year-old patients (Table 2). Rates of non-histology confirmed PC decreased through the whole study period (1994-2015) with a significant EAPC of $-2.23 \%$ (Figure $2 \mathrm{f}$ ).

The increase in incidence rates applied for all age subgroups in our population, however the rate of increase was more pronounced in older age groups, as reflected by an EAPC of $1.45 \%$ in patients $\geq 55$ years old versus $0.59 \%$ in $<55$ year olds (Figure $2 \mathrm{~g}, \mathrm{i}$ ). The difference in annual percent change by age group was larger in Non-PNETs, with an EAPC of $0.6 \%$ for $<55$-year-old patients compared to $6.80 \%$ in $\geq 55$ year olds (Figure $2 \mathrm{~h}, \mathrm{j}$ ). 
Table 2. Incidence of pancreatic cancer (PC) in Girona, 1994-2015. European standard population of 2013 (ASRE13) according to histology. Non-PNET-Pancreatic carcinomas non-neuroendocrine. PNET—Pancreatic neuroendocrine tumours. Non-HC-Pancreatic cancers non-histologically confirmed.

\begin{tabular}{|c|c|c|c|c|c|c|c|c|c|c|c|c|c|c|c|c|}
\hline & \multicolumn{4}{|c|}{ All PC } & \multicolumn{4}{|c|}{ Non-PNETs } & \multicolumn{4}{|c|}{ PNETs } & \multicolumn{4}{|c|}{ PC Non-HC } \\
\hline & $n$ & $\%$ Total & $\mathbf{A S R}_{\mathrm{E} 13}$ & $95 \%$ CI & $n$ & \% Total & ASR $_{\text {E13 }}$ & $95 \% \mathrm{CI}$ & $n$ & \% Total & $\mathrm{ASR}_{\mathrm{E} 13}$ & $95 \% \mathrm{CI}$ & $n$ & $\%$ Total & ASR $_{\mathrm{E} 13}$ & $95 \% \mathrm{CI}$ \\
\hline \multicolumn{17}{|l|}{ Sex } \\
\hline Female & 737 & 46 & 10.82 & $(10.05-11.65)$ & 288 & 40.45 & 4.46 & $(3.95-5.01)$ & 28 & 43.08 & 0.41 & $(0.27-0.6)$ & 421 & 51.03 & 5.96 & $(5.4-6.57)$ \\
\hline Male & 865 & 54 & 15.8 & $(14.75-16.91)$ & 424 & 59.55 & 7.35 & $(6.66-8.1)$ & 37 & 56.92 & 0.6 & $(0.42-0.84)$ & 404 & 48.97 & 7.85 & $(7.09-8.68)$ \\
\hline \multicolumn{17}{|c|}{ Age Group (years) } \\
\hline $15-44$ & 52 & 3.25 & 0.85 & $(0.63-1.12)$ & 27 & 3.79 & 0.44 & $(0.29-0.65)$ & 19 & 29.23 & 0.3 & $(0.18-0.48)$ & 6 & 0.73 & 0.1 & $(0.04-0.22)$ \\
\hline $45-54$ & 150 & 9.36 & 8.16 & $(6.9-9.58)$ & 106 & 14.89 & 5.75 & $(4.7-6.96)$ & 13 & 20 & 0.7 & $(0.37-1.2)$ & 31 & 3.76 & 1.71 & $(1.16-2.43)$ \\
\hline $55-64$ & 281 & 17.54 & 19.32 & (17.13-21.72) & 191 & 26.83 & 13.14 & (11.34 15.14) & 10 & 15.38 & 0.69 & $(0.33-1.26)$ & 80 & 9.7 & 5.5 & $(4.36-6.85)$ \\
\hline $65-74$ & 432 & 26.97 & 35.66 & $(32.38-39.19)$ & 221 & 31.04 & 18,23 & (15.91-20.8) & 11 & 16.92 & 0.9 & $(0.45-1.62)$ & 200 & 24.24 & 16.52 & $(14.31-18.98)$ \\
\hline $75+$ & 687 & 42.88 & 61.83 & (57.28-66.66) & 167 & 23.46 & 14.87 & (12.69 17.32) & 12 & 18.46 & 1.06 & $(0.55-1.86)$ & 508 & 61.58 & 45.91 & (41.99-50.1) \\
\hline \multicolumn{17}{|l|}{ STAGE } \\
\hline I & 21 & 1.31 & 0.15 & $(0.07-0.32)$ & 9 & 1.26 & 0.08 & $(0.02-0.21)$ & 8 & 12.31 & 0.05 & $(0.01-0.17)$ & 4 & 0.48 & 0.03 & $(0.01-0.14)$ \\
\hline IIA & 37 & 2.31 & 0.31 & $(0.22-0.43)$ & 25 & 3.51 & 0.21 & $(0.14-0.32)$ & 5 & 7.69 & 0.04 & $(0.01-0.09)$ & 7 & 0.85 & 0.06 & $(0.02-0.12)$ \\
\hline IIB & 70 & 4.37 & 0.59 & $(0.46-0.75)$ & 62 & 8.71 & 0.53 & $(0.4-0.68)$ & 1 & 1.54 & 0.01 & $(0-0.04)$ & 7 & 0.85 & 0.06 & $(0.02-0.12)$ \\
\hline III & 70 & 4.37 & 0.58 & $(0.45-0.74)$ & 43 & 6.04 & 0.36 & $(0.26-0.49)$ & 2 & 3.08 & 0.01 & $(0-0.05)$ & 25 & 3.03 & 0.21 & $(0.13-0.31)$ \\
\hline IV & 415 & 25.90 & 3.40 & $(3.07-3.79)$ & 251 & 35.25 & 2.06 & $(1.8-2.37)$ & 21 & 32.31 & 0.16 & $(0.1-0.28)$ & 143 & 17.33 & 1.18 & $(0.99-1.42)$ \\
\hline TOTAL & 1602 & & 13.19 & $(12.55-13.85)$ & 712 & & 5.87 & $(5.44-6.32)$ & 65 & & 0.49 & $(0.38-0.63)$ & 825 & & 6.83 & $(6.37-7.32)$ \\
\hline
\end{tabular}




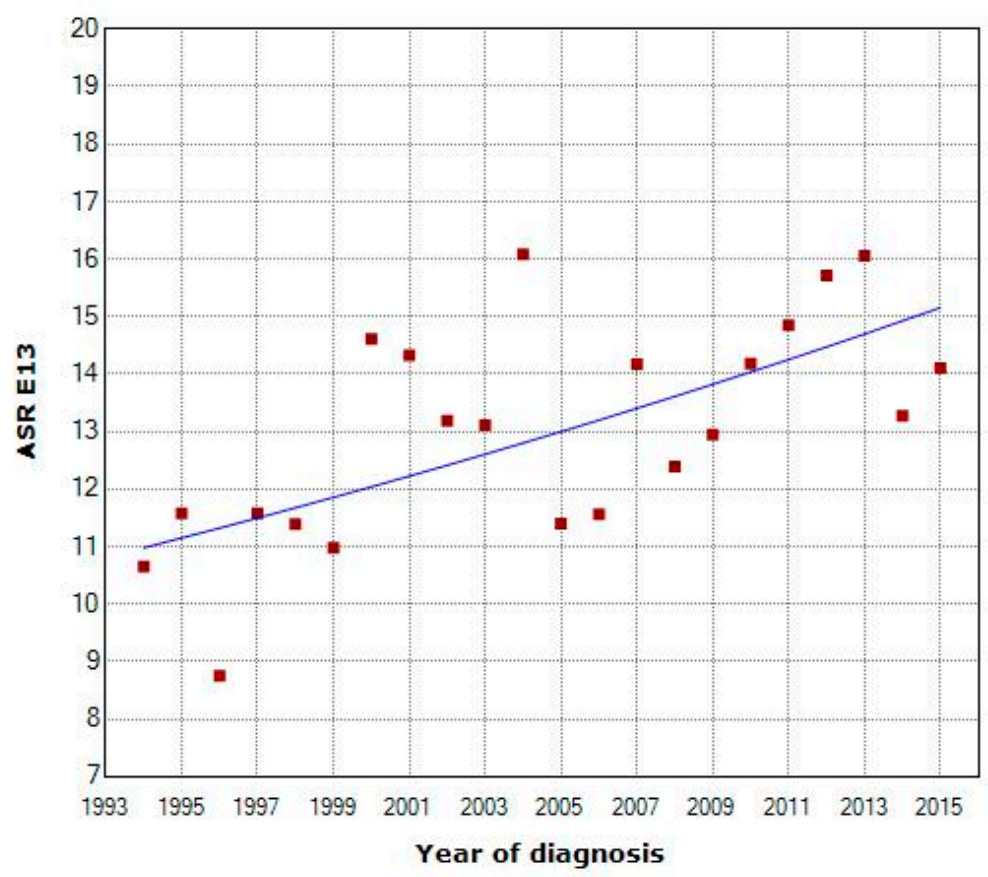

\section{- Observed \\ 1994.0-2015.0 APC $=1.55^{\circ}$}

- Indicates that the Annual Percent Change (APC) is significantly different from zero at the alpha $=0.05$ level Final Selected Model: 0 Joinpoints.

(a)

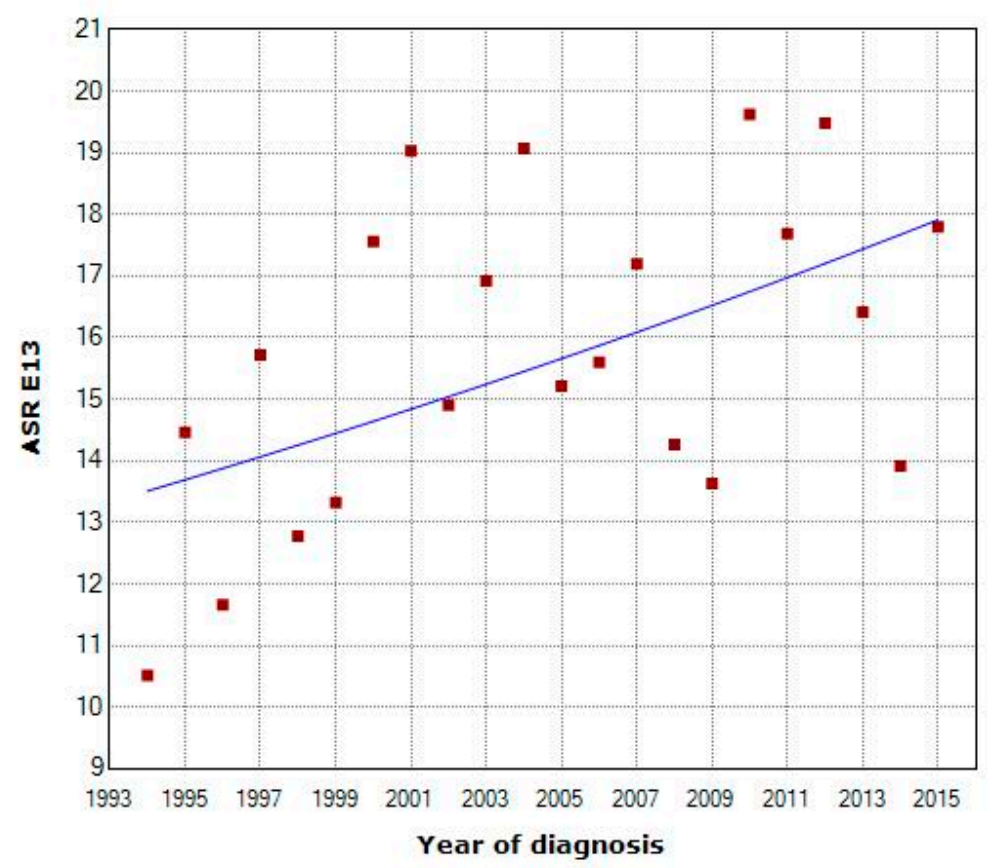

Observed
1994.0-2015.0 APC $=1.35^{\circ}$

- Indicates that the Annual Percent Change (APC) is significantly different from zero at the alpha $=0.05$ level Final Selected Model: 0 Joinpoints.

(b)

Figure 2. Cont. 

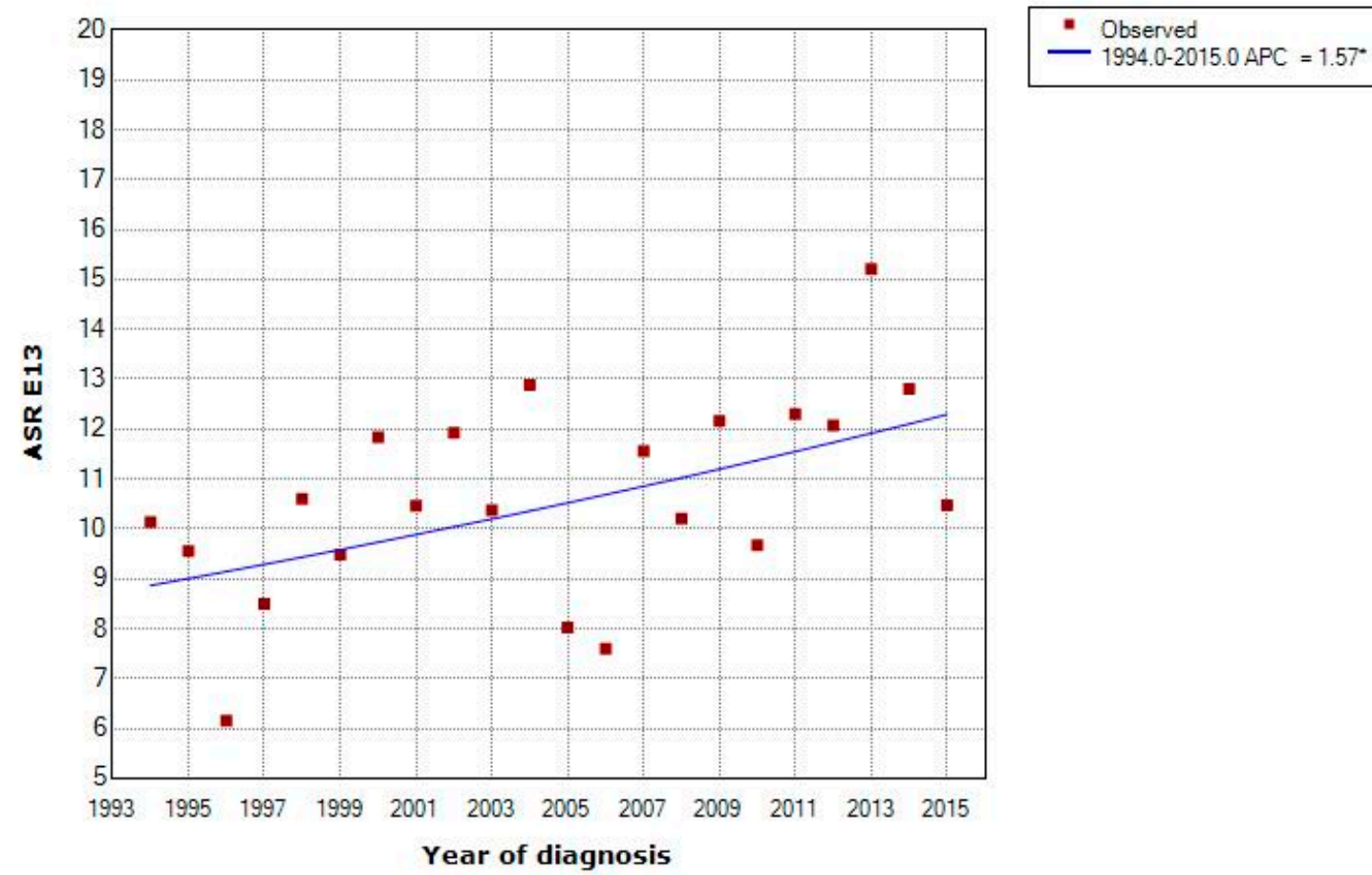

- Indicates that the Annual Percent Change (APC) is significantly different from zero at the alpha $=0.05$ level Final Selected Model: 0 Joinpoints.

(c)

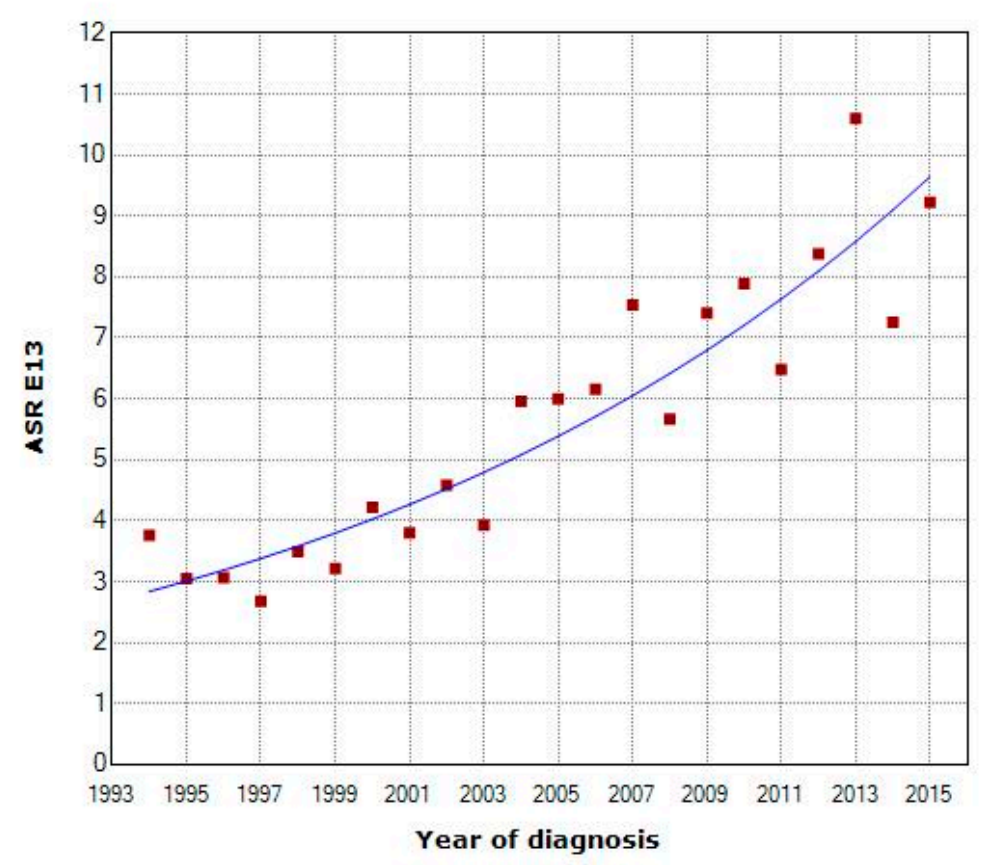

- Indicates that the Annual Percent Change (APC) is significantly different from zero at the alpha $=0.05$ level Final Selected Model: 0 Joinpoints.

(d)

Figure 2. Cont. 


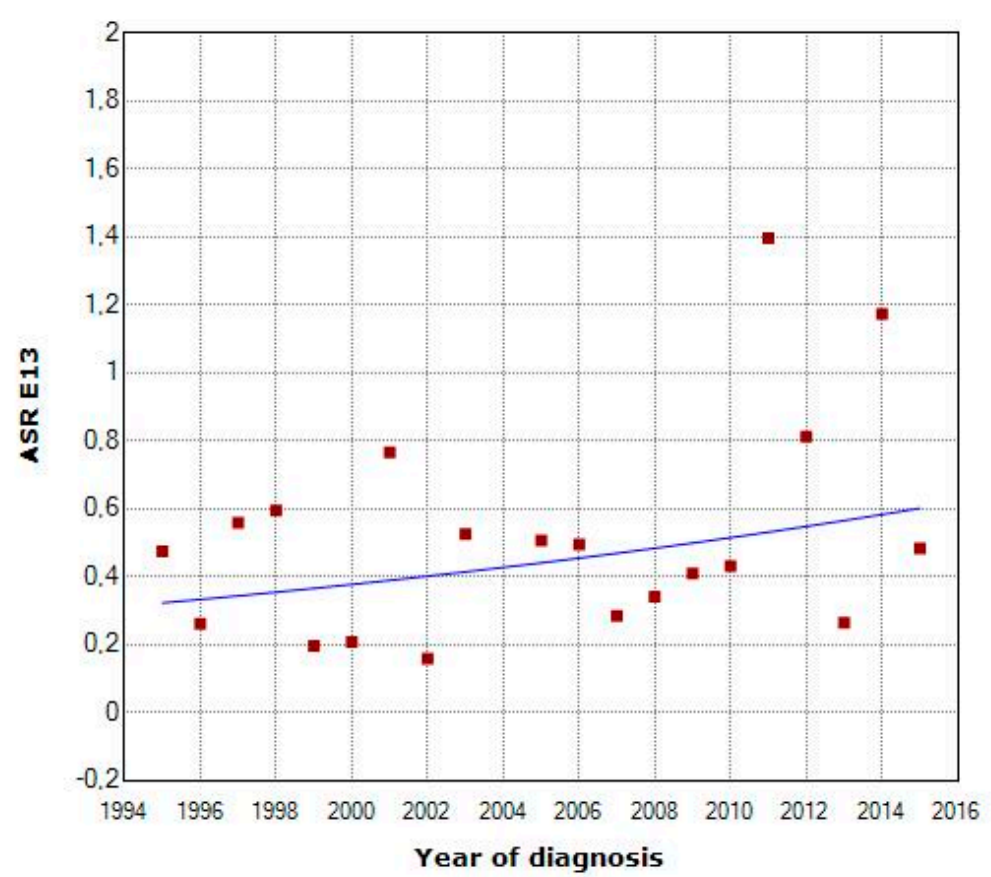

- Indicates that the Annual Percent Change (APC) is significantly different from zero at the alpha $=0.05$ level Final Selected Model: 0 Joinpoints.

(e)

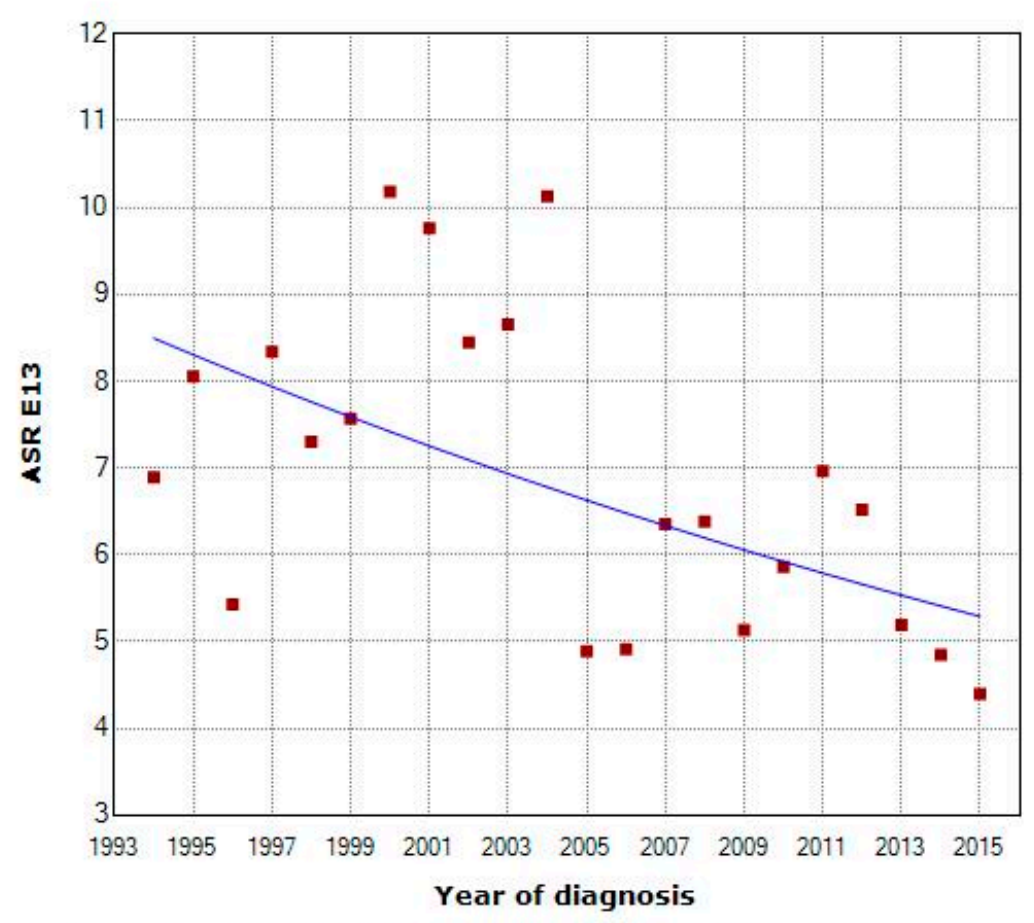

- Indicates that the Annual Percent Change (APC) is significantly different from zero at the alpha $=0.05$ level. Final Selected Model: 0 Joinpoints.

(f)

Figure 2. Cont. 


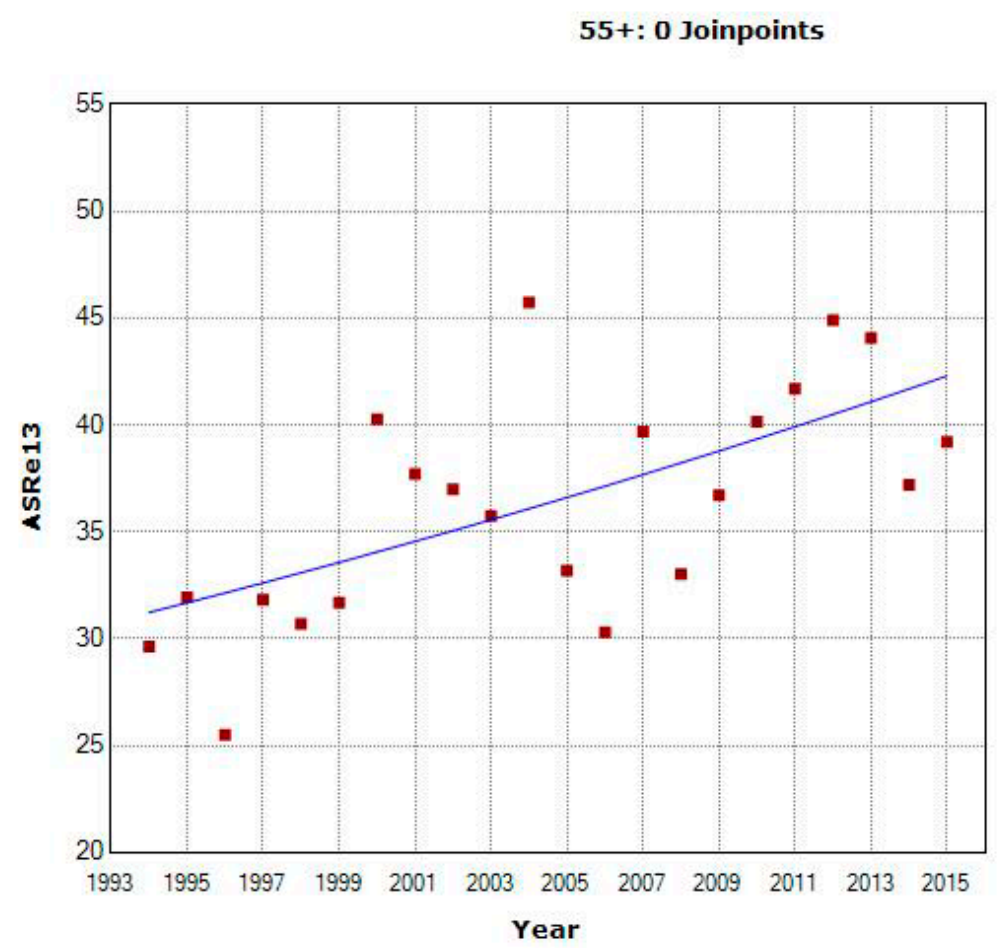

- Indicates that the Annual Percent Change (APC) is significantly different from zero at the alpha $=0.05$ level Final Selected Model: 0 Joinpoints.

$(\mathrm{g})$

55+: 0 Joinpoints
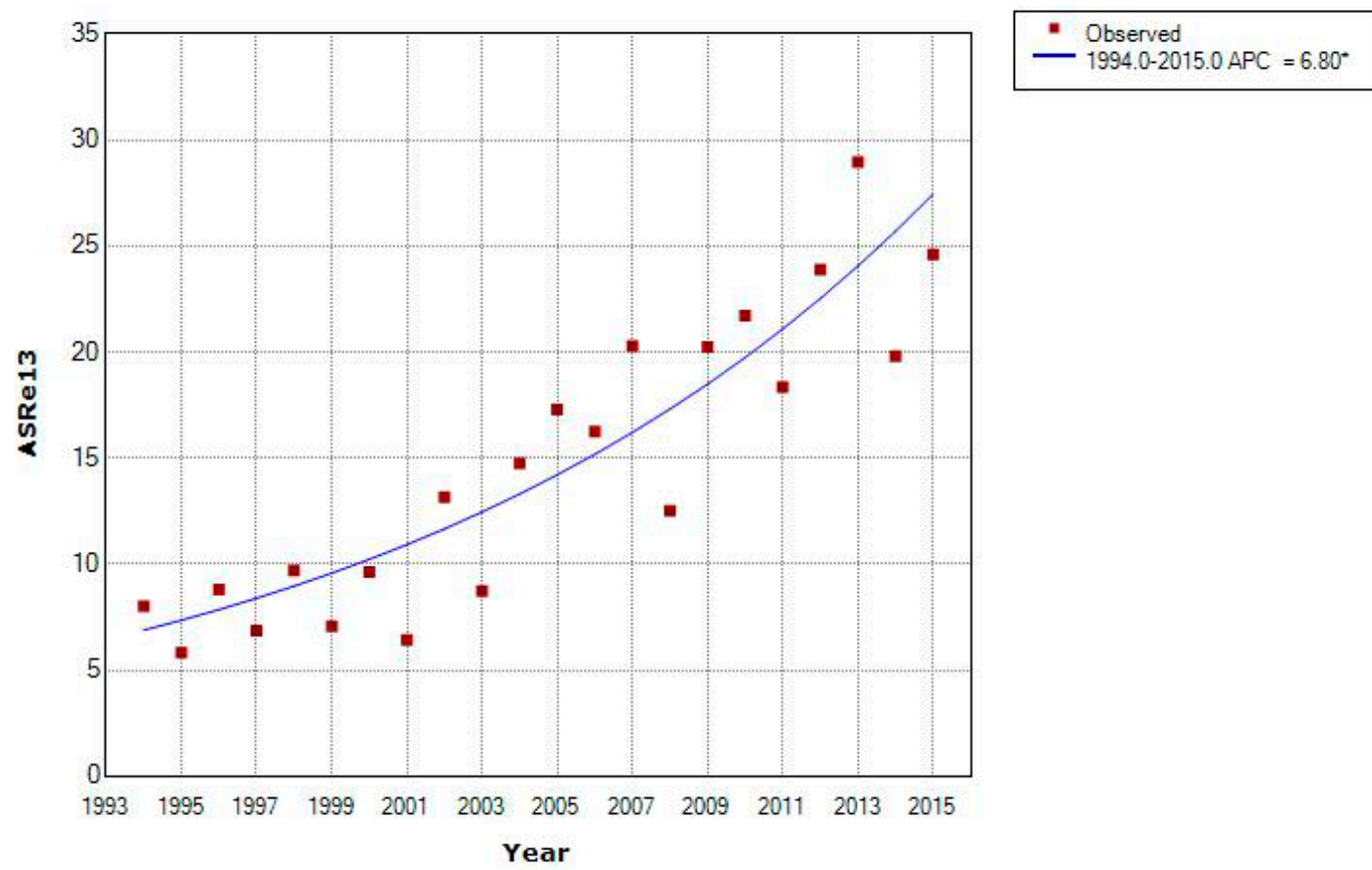

- Indicates that the Annual Percent Change (APC) is significantly different from zero at the alpha $=0.05$ level. Final Selected Model: 0 Joinpoints.

(h)

Figure 2. Cont. 


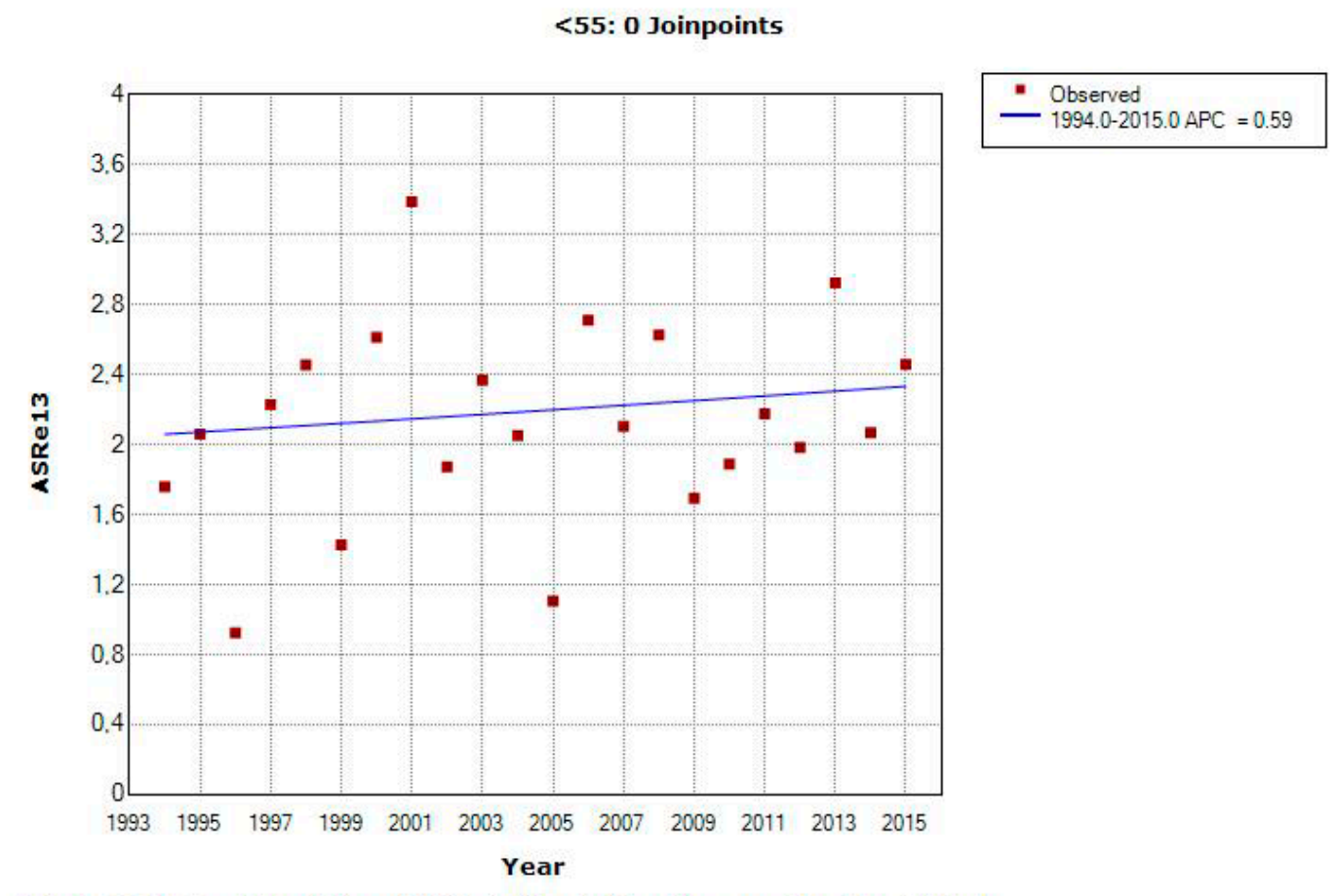

-Indicates that the Annual Percent Change (APC) is significantly different from zero at the alpha $=0.05$ level. Final Selected Model: 0 Joinpoints.

(i)

$<55$ : 0 Joinpoints

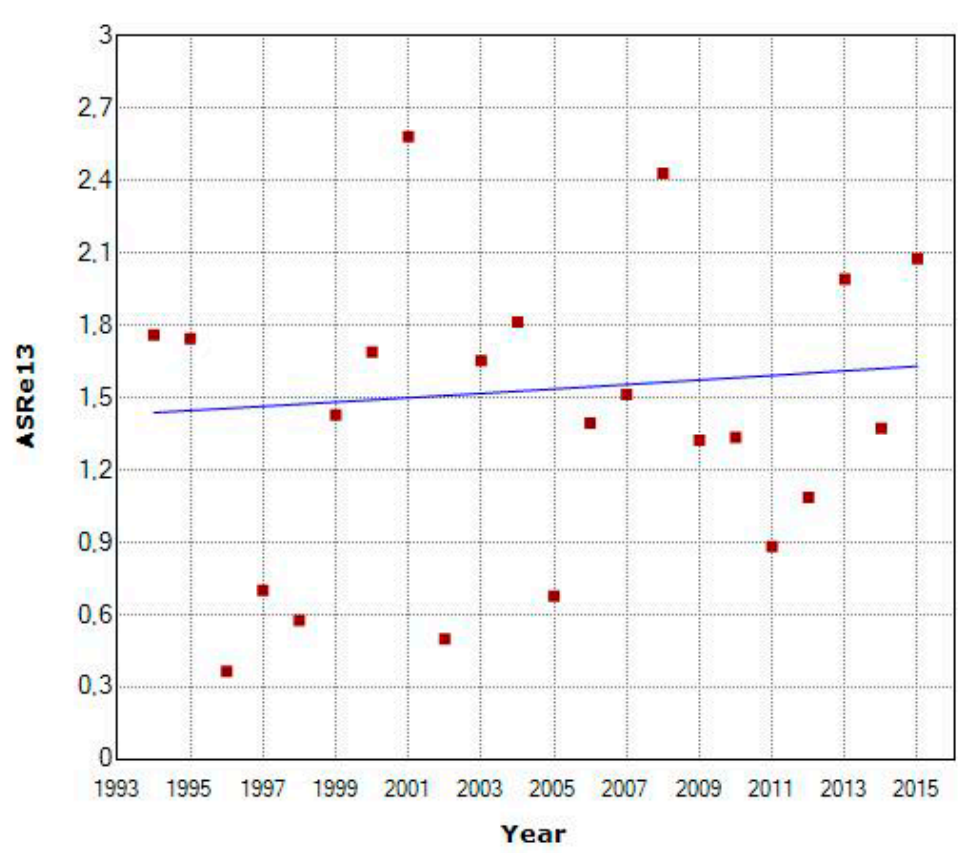

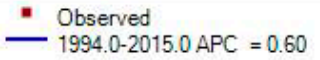

- Indicates that the Annual Percent Change (APC) is significantly different from zero at the alpha $=0.05$ level. Final Selected Model: 0 Joinpoints.

(j)

Figure 2. Trends in annual pancreatic tumors incidence (ASR $\left.\mathrm{A}_{\mathrm{E} 13}\right)$ according to sex; (a) both sexes; (b) male; (c) female; according to histological groups; (d) non PNETS; (e) PNETs; (f) non histological confirmation. According to age groups; (g) All PC $\geq 55$ years-old; (h) Exocrine tumours $\geq 55$ years-old; (i) All PC $<55$ years-old; (j) Exocrine tumours $<55$ years-old. 


\subsection{Survival}

The overall 5-year RS was 7.05\% (95\% CI: 5.63; 8.84), higher in men (7.34\%) than in women (6.75\%) (Supplementary Figure S1). The survival rate decreased with advancing age at diagnosis, the 5-year RS dropped from $34.23 \%$ in young patients (15-44 years) to $2.04 \%$ in older patients (75+ years) (Figures 3 and 4 ). According to the stage at diagnosis, stage IIA showed a 5-year RS of $46.14 \%$ (95\% CI 36.14; 58.91) in contrast to the $4.36 \%(95 \%$ CI $2.61 ; 7.29)$ of stage IV. Trends in 5-year RS increased from $3.27 \%$ $(95 \%$ CI $1.69 ; 6.35)$ in $1994-98$ to $13.1 \%(95 \%$ CI 9.98; 17.2) in 2010-15. No differences in survival rates between the geographical areas of Girona province have been found (Table 3 and Figure 3a).

For non-PNETs and non-HC PC, overall 5-year RS was higher in men (4.75\%) than in women (2.9\%). The survival rate was lower with increasing age, the 5-year RS decreased from $15.79 \%$ in young patients (15-44 years) to $1.07 \%$ in older patients (75+ years). As for the stage at diagnosis, stage IIA presented the best survival with a 5-year RS of $28.25 \%(95 \%$ CI $14.08 ; 56.67)$ and stage IV patients carried the worst 5-year RS: $0.55 \%(95 \%$ CI 0.08; 3.89). Trends in 5-year RS rose from $1.06 \%(95 \%$ CI $0.36 ; 3.1)$ in $1994-98$ to $7.76 \%(95 \%$ CI 5.22; 11.53) in 2010-15. No differences in survival between the geographical areas studied have been found (Table 4 and Figure $3 b$ ).

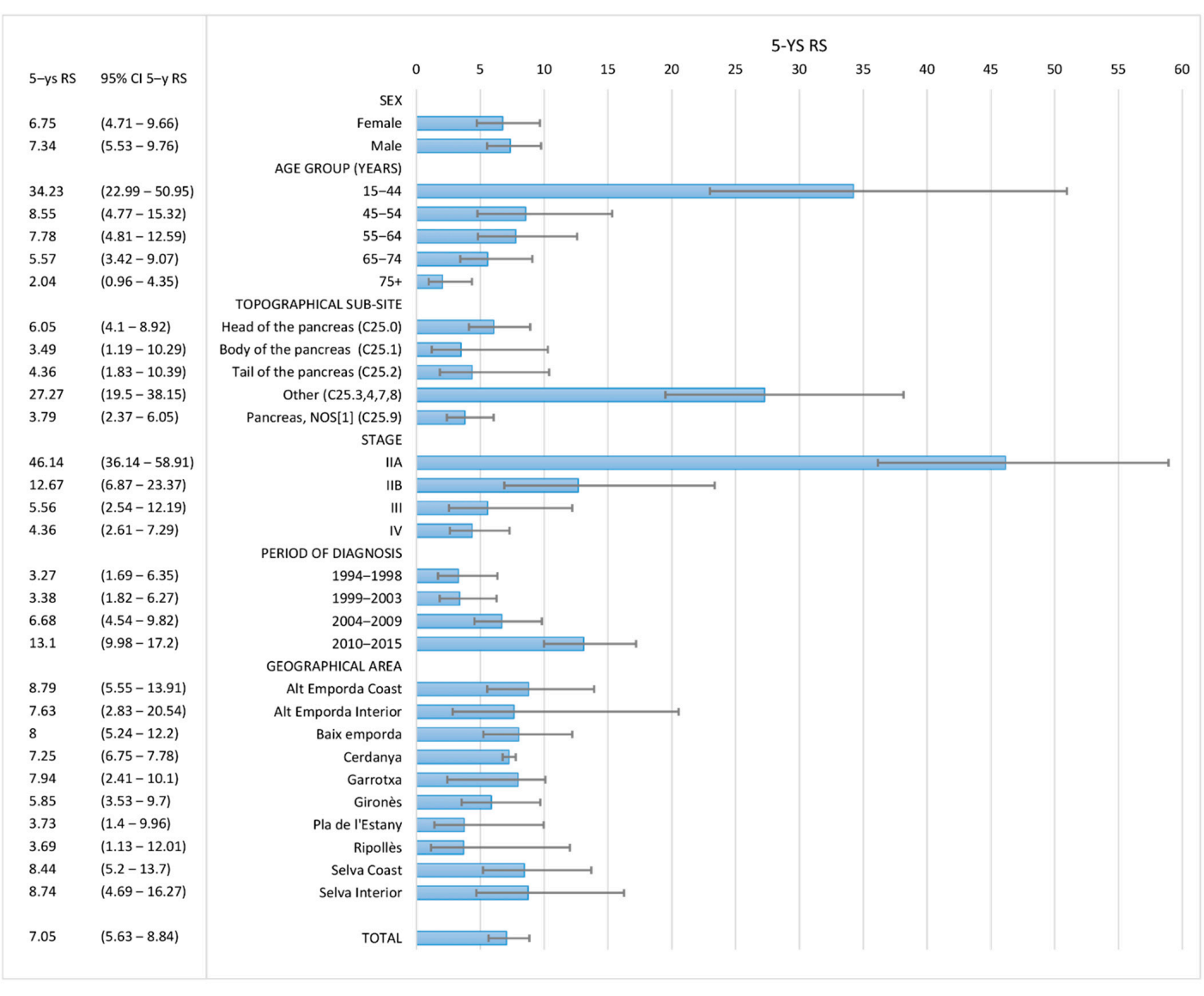

(a)

Figure 3. Cont. 


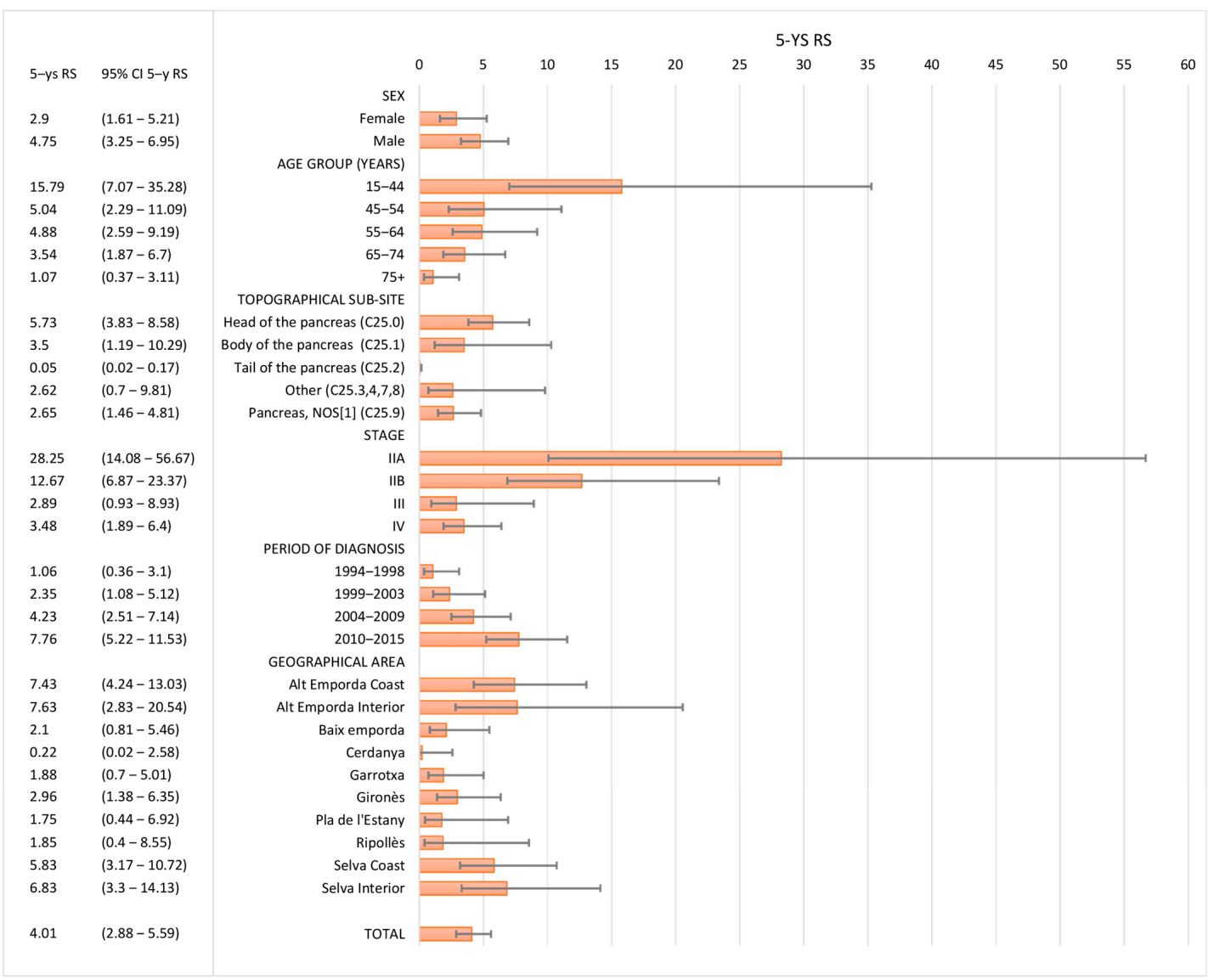

(b)

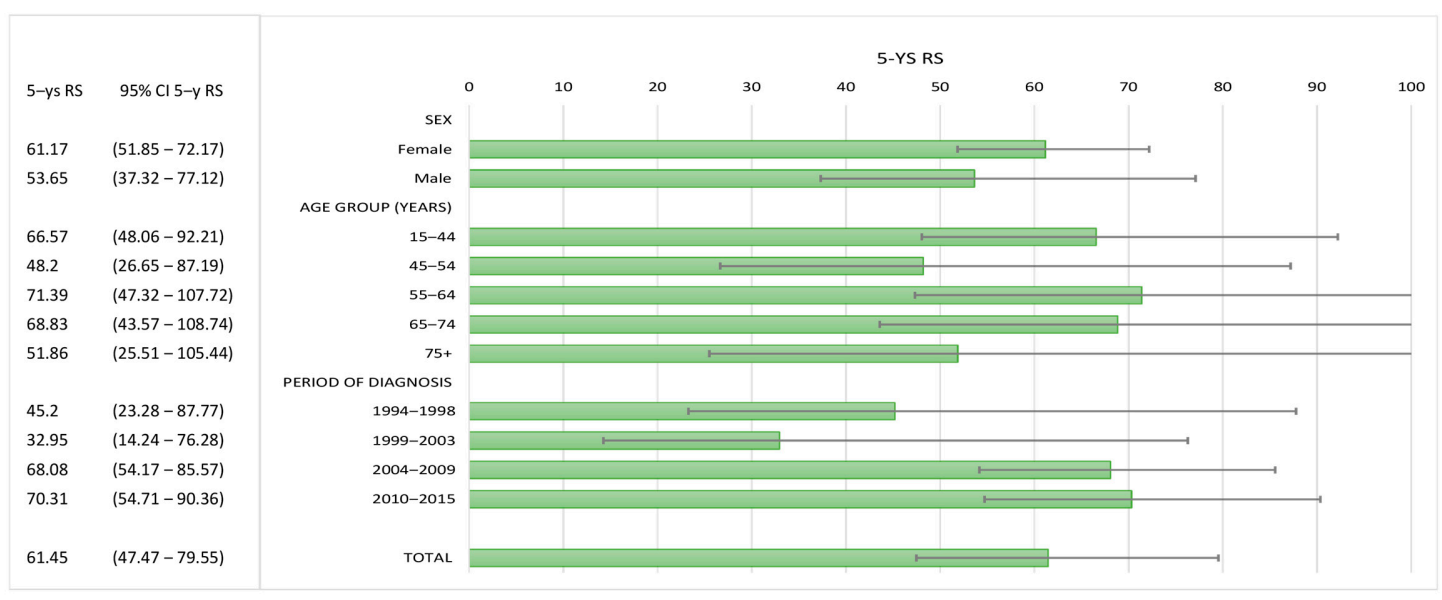

(c)

Figure 3. 5-year relative survival for all pancreatic cancers-PC (a), Pancreatic carcinomas non-neuroendocrine-Non PNETs (b) and Pancreatic neuroendocrine tumors-PNETs (c) by sex, stage, period of diagnosis, sub-site and county. Girona province, 1994-2015. 


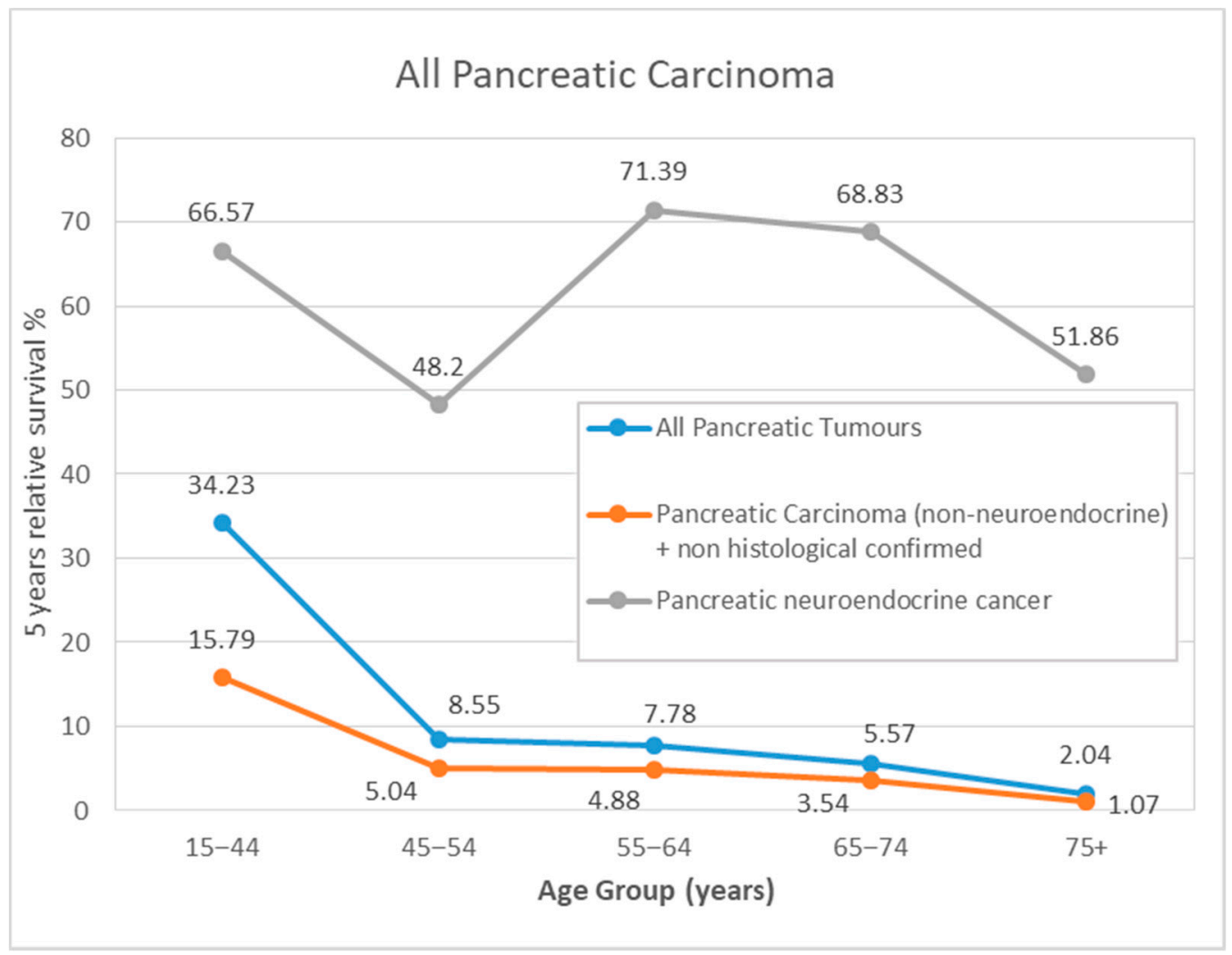

Figure 4. Age-specific period estimates of 5-year relative survival for all patients with pancreatic cancer diagnosed between 1994-2015, and according to histology.

Finally, patients with PNETs had the best survival with a 5-year RS of $61.45 \%$ (95\% CI 47.47; 79.55) (Figure 4). Due the low number of cases we only analysed survival according to sex, age group and period of diagnosis. No differences were observed by age or sex. The 5-year RS increased during the study period from $45.2 \%(95 \%$ CI $23.28 ; 87.77)$ in $1994-1998$ to 70.31 (95\% CI 54.71; 90.36) in 2010-2015 (Table 5 and Figure 3c). 
Table 3. One and 5-year observed and relative survival for all pancreatic cancers by sex, age, stage, period of diagnosis, sub-site and county. Girona province, $1994-2015$.

\begin{tabular}{|c|c|c|c|c|c|c|c|c|c|c|}
\hline & \multicolumn{5}{|c|}{ Observed Survival (OS) } & \multicolumn{5}{|c|}{ Relative Survival (RS) } \\
\hline & n Cases & $1-y$ OS & 95\% CI 1-y OS & $5-y$ OS & $95 \%$ CI 5-y OS & n Cases & $1-y$ RS & 95\% CI 1-y RS & 5-ys RS & 95\% CI 5-y RS \\
\hline \multicolumn{11}{|l|}{ SEX } \\
\hline Female & 681 & 20.46 & $(17.6-23.79)$ & 4.18 & $(2.76-6.34)$ & 681 & 26.46 & $(23.04-30.38)$ & 6.75 & $(4.71-9.66)$ \\
\hline Male & 800 & 22.47 & $(19.69-25.65)$ & 5.83 & $(4.28-7.95)$ & 800 & 24.12 & $(21.28-27.34)$ & 7.34 & $(5.53-9.76)$ \\
\hline \multicolumn{11}{|l|}{ AGE GROUP (YEARS) } \\
\hline $15-44$ & 51 & 54.65 & $(42.51-70.25)$ & 33.91 & $(22.57-50.95)$ & 51 & 54.73 & $(42.72-70.11)$ & 34.23 & $(22.99-50.95)$ \\
\hline $45-54$ & 146 & 37.62 & $(30.37-46.61)$ & 8.39 & $(4.6-15.31)$ & 146 & 37.75 & $(30.52-46.68)$ & 8.55 & $(4.77-15.32)$ \\
\hline $55-64$ & 262 & 30.02 & $(24.8-36.36)$ & 7.37 & $(4.51-12.05)$ & 259 & 30.62 & $(25.33-37.02)$ & 7.78 & $(4.81-12.59)$ \\
\hline $65-74$ & 400 & 23.98 & $(20.05-28.67)$ & 4.69 & $(2.82-7.8)$ & 398 & 24.64 & $(20.62-29.43)$ & 5.57 & $(3.42-9.07)$ \\
\hline $75+$ & 622 & 9.92 & $(7.8-12.63)$ & 1.26 & $(0.57-2.77)$ & 618 & 10.72 & $(8.43-13.64)$ & 2.04 & $(0.96-4.35)$ \\
\hline \multicolumn{11}{|l|}{ TOPOGRAPHICAL SUB-SITE } \\
\hline Head of the pancreas (C25.0) & 644 & 26.26 & $(23-29.99)$ & 4.26 & $(2.77-6.53)$ & 644 & 30.7 & $(27.09-34.79)$ & 6.05 & $(4.1-8.92)$ \\
\hline Body of the pancreas (C25.1) & 106 & 19.56 & $(13.13-29.15)$ & 2.06 & $(0.52-8.11)$ & 106 & 19.16 & $(13.28-27.64)$ & 3.49 & $(1.19-10.29)$ \\
\hline Tail of the pancreas (C25.2) & 82 & 18.05 & (11.28-28.88) & 4.51 & $(1.55-13.1)$ & 82 & 19.9 & $(13.61-29.09)$ & 4.36 & $(1.83-10.39)$ \\
\hline $\begin{array}{l}\text { Other specified parts of the } \\
\text { pancreas }(C 25 \cdot 3,4,7,8)\end{array}$ & 91 & 45.75 & $(36.53-57.3)$ & 30.84 & $(22.23-42.79)$ & 91 & 41.14 & $(32.93-51.4)$ & 27.27 & $(19.5-38.15)$ \\
\hline Pancreas, NOS (C25.9) & 558 & 12.91 & $(10.36-16.1)$ & 2.71 & $(1.56-4.7)$ & 558 & 15.41 & $(12.48-19.02)$ & 3.79 & $(2.37-6.05)$ \\
\hline \multicolumn{11}{|l|}{ STAGE } \\
\hline I & 21 & - & (NA-NA) & - & (NA-NA) & 21 & - & (NA-NA) & 0.26 & (NA-NA) \\
\hline IIA & 37 & 62.49 & $(48.16-81.1)$ & 36.87 & (22.79-59.63) & 37 & 66 & $(53.63-81.23)$ & 46.14 & $(36.14-58.91)$ \\
\hline IIB & 69 & 60.58 & $(49.81-73.68)$ & 15.4 & $(7.58-31.31)$ & 69 & 56.12 & $(45.76-68.81)$ & 12.67 & $(6.87-23.37)$ \\
\hline III & 70 & 33.34 & $(23.88-46.54)$ & 4.62 & $(1.54-13.89)$ & 70 & 37.55 & $(29.73-47.43)$ & 5.56 & $(2.54-12.19)$ \\
\hline IV & 414 & 19.11 & (15.57-23.45) & 2.78 & $(1.37-5.63)$ & 414 & 21.1 & $(17.43-25.53)$ & 4.36 & $(2.61-7.29)$ \\
\hline \multicolumn{11}{|l|}{ PERIOD OF DIAGNOSIS } \\
\hline 1994-1998 & 217 & 16.69 & $(12.39-22.49)$ & 2.78 & $(1.26-6.12)$ & 217 & 18.09 & $(13.68-23.91)$ & 3.27 & $(1.69-6.35)$ \\
\hline 1999-2003 & 289 & 14.18 & $(10.64-18.89)$ & 2.48 & $(1.19-5.16)$ & 289 & 16.39 & $(12.46-21.55)$ & 3.38 & $(1.82-6.27)$ \\
\hline 2004-2009 & 415 & 23.04 & $(19.3-27.5)$ & 4.66 & $(3-7.22)$ & 415 & 27.44 & $(23.51-32.02)$ & 6.68 & $(4.54-9.82)$ \\
\hline 2010-2015 & 560 & 26.45 & $(22.89-30.55)$ & 9.65 & $(7.09-13.13)$ & 560 & 31.45 & $(27.6-35.83)$ & 13.1 & $(9.98-17.2)$ \\
\hline \multicolumn{11}{|l|}{ GEOGRAPHICAL AREA } \\
\hline Alt Empordà Coast & 224 & 21.99 & $(17.06-28.35)$ & 5.98 & $(3.42-10.46)$ & 224 & 26.25 & $(21.11-32.66)$ & 8.79 & $(5.55-13.91)$ \\
\hline Alt Empordà Interior & 38 & 14.75 & $(6.25-34.85)$ & 7.38 & $(2-27.16)$ & 38 & 13.69 & $(7.09-26.42)$ & 7.63 & $(2.83-20.54)$ \\
\hline Baix Empordà & 262 & 23.14 & (18.49-28.95) & 6.03 & $(3.5-10.4)$ & 262 & 24.94 & $(20.23-30.74)$ & 8 & $(5.24-12.2)$ \\
\hline Cerdanya & 24 & 12.5 & $(4.34-36.03)$ & 4.17 & $(0.61-28.38)$ & 24 & 13.87 & $(8.82-21.83)$ & 7.25 & $(6.75-7.78)$ \\
\hline Garrotxa & 129 & 19.19 & $(13.42-27.45)$ & 4.26 & $(1.82-9.96)$ & 129 & 21.69 & $(15.77-29.83)$ & 4.94 & $(2.41-10.1)$ \\
\hline Gironès & 343 & 21.09 & $(17.11-26)$ & 4.02 & $(2.21-7.33)$ & 343 & 25.98 & $(21.85-30.88)$ & 5.85 & $(3.53-9.7)$ \\
\hline Pla De L'Estany & 62 & 26.28 & $(17.26-40.02)$ & 3.5 & $(0.9-13.61)$ & 62 & 34.21 & $(25.25-46.36)$ & 3.73 & $(1.4-9.96)$ \\
\hline Ripollès & 87 & 17.43 & $(10.87-27.96)$ & 3.08 & $(0.81-11.71)$ & 86 & 18.29 & $(11.55-28.97)$ & 3.69 & $(1.13-12.01)$ \\
\hline Selva Coast & 204 & 27.88 & $(22.19-35.01)$ & 5.93 & $(3-11.73)$ & 204 & 30.55 & $(24.71-37.78)$ & 8.44 & $(5.2-13.7)$ \\
\hline Selva Interior & 108 & 14.18 & $(8.88-22.64)$ & 5.88 & $(2.61-13.26)$ & 108 & 17.38 & $(11.51-26.24)$ & 8.74 & $(4.69-16.27)$ \\
\hline TOTAL & 1481 & 21.54 & $(19.5-23.79)$ & 5.07 & $(3.95-6.51)$ & 1481 & 24.94 & $(22.72-27.38)$ & 7.05 & $(5.63-8.84)$ \\
\hline
\end{tabular}


Table 4. One and 5-year observed and relative survival for non-PNETs and non-HC PC by sex, age, stage, period of diagnosis, sub-site and county. Girona province, $1994-2015$.

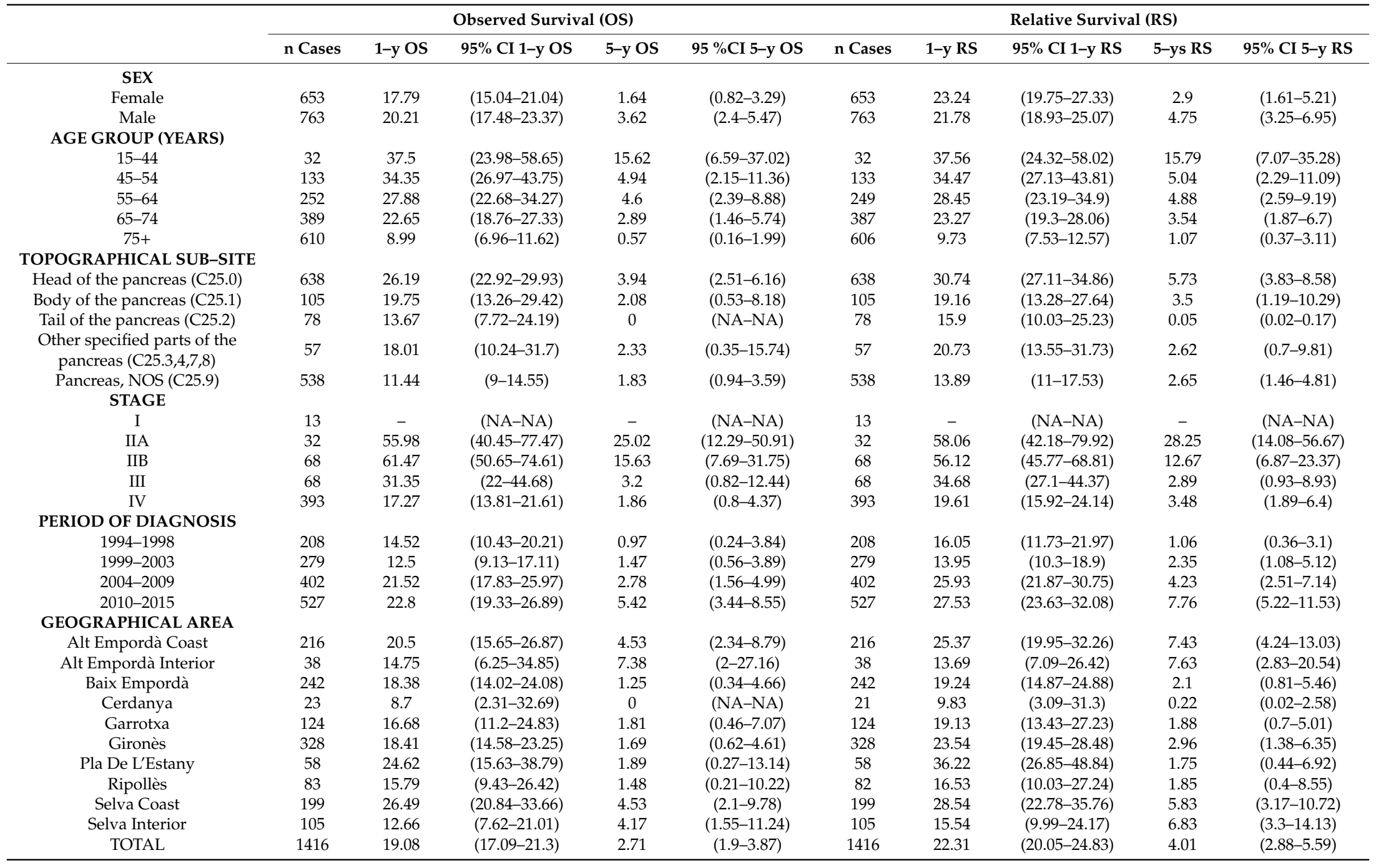


Table 5. One and 5-year observed and relative survival for PNETs by sex, age, stage, period of diagnosis, sub-site and county. Girona province, $1994-2015$.

\begin{tabular}{|c|c|c|c|c|c|c|c|c|c|c|}
\hline & \multicolumn{5}{|c|}{ Observed Survival (OS) } & \multicolumn{5}{|c|}{ Relative Survival (RS) } \\
\hline & n Cases & $1-y$ OS & $95 \%$ CI 1-y OS & $5-y$ OS & $95 \%$ CI 5-y OS & n Cases & $1-y$ RS & 95\% CI 1-y RS & 5-ys RS & 95\% CI 5-y RS \\
\hline \multicolumn{11}{|l|}{ SEX } \\
\hline Female & 28 & 81.82 & $(68.57-97.62)$ & 68.33 & (52.12-89.56) & 28 & 63.63 & (55.42-73.06) & 61.17 & (51.85-72.17) \\
\hline Male & 37 & 67.27 & $(53.65-84.34)$ & 51.38 & $(36.97-71.42)$ & 37 & 65.32 & $(51.12-83.45)$ & 53.65 & $(37.32-77.12)$ \\
\hline \multicolumn{11}{|l|}{ AGE GROUP (YEARS) } \\
\hline $15-44$ & 19 & 83.88 & $(68.71-100)$ & 66.09 & (47.14-92.65) & 19 & 84 & $(69.21-101.94)$ & 66.57 & $(48.06-92.21)$ \\
\hline $45-54$ & 13 & 69.23 & $(48.19-99.47)$ & 47.47 & $(24.93-90.4)$ & 13 & 69.39 & $(49.09-98.07)$ & 48.2 & $(26.65-87.19)$ \\
\hline $55-64$ & 10 & 80 & $(58.68-100)$ & 68.57 & $(44.47-100)$ & 10 & 80.36 & (59.95-107.72) & 71.39 & $(47.32-107.72)$ \\
\hline $65-74$ & 11 & 71.59 & $(48.84-100)$ & 61.36 & (37.69-99.92) & 11 & 72.56 & $(50.57-104.1)$ & 68.83 & $(43.57-108.74)$ \\
\hline $75+$ & 12 & 58.33 & $(36.16-94.1)$ & 43.75 & $(20.86-91.77)$ & 12 & 61.42 & $(39.06-96.58)$ & 51.86 & $(25.51-105.44)$ \\
\hline \multicolumn{11}{|l|}{ TOPOGRAPHICAL SUB-SITE } \\
\hline Head of the pancreas (C25.0) & 6 & 33.33 & $(10.75-100)$ & 33.33 & $(10.75-100)$ & 6 & 33.51 & $(12.7-88.41)$ & 34.11 & $(12.93-90)$ \\
\hline Body of the pancreas (C25.1) & 1 & 0 & (NA-NA) & 0 & (NA-NA) & 1 & 0.03 & $(0-0.22)$ & 0.03 & $(0-0.22)$ \\
\hline Tail of the pancreas (C25.2) & 4 & 100 & $(100-100)$ & 75 & (42.59-100) & 4 & 100 & (100-100) & 82.47 & $(50.94-133.54)$ \\
\hline $\begin{array}{l}\text { Other specified parts of the } \\
\text { pancreas (C25.3.4, }\end{array}$ & 34 & 91.18 & $(82.12-100)$ & 76.55 & $(62.56-93.67)$ & 34 & 87.77 & (75.23-102.4) & 81.77 & (64.89-103.02) \\
\hline \multirow{2}{*}{\multicolumn{11}{|c|}{ STAGE }} \\
\hline & & & & & & & & & & \\
\hline I & 8 & - & (NA-NA) & - & (NA-NA) & 8 & - & (NA-NA) & - & (NA-NA) \\
\hline IIA & 5 & 100 & $(100-100)$ & 100 & (100-100) & 5 & 100 & (100-100) & 106.46 & $(106.46-106.46)$ \\
\hline IIB & 1 & 0 & (NA-NA) & 0 & (NA-NA) & 1 & 0.03 & $(0-0.22)$ & 0.03 & $(0-0.22)$ \\
\hline III & 2 & 100 & $(100-100)$ & 50 & $(12.5-100)$ & 2 & 100 & $(100-100)$ & 57.71 & $(18.81-177.01)$ \\
\hline IV & 21 & 51.95 & $(34.31-78.66)$ & 28.05 & $(11.96-65.81)$ & 21 & 51.45 & $(36.42-72.7)$ & 34.83 & $(20.62-58.85)$ \\
\hline \multicolumn{11}{|l|}{ PERIOD OF DIAGNOSIS } \\
\hline 1994-1998 & 9 & 66.67 & $(42-100)$ & 44.44 & $(21.41-92.27)$ & 9 & 67.18 & $(43.7-103.27)$ & 45.2 & $(23.28-87.77)$ \\
\hline 1999-2003 & 10 & 60 & (36.17-99.52) & 30 & (11.64-77.32) & 10 & 60.38 & $(37.63-96.87)$ & 32.95 & (14.24-76.28) \\
\hline 2004-2009 & 13 & 69.23 & (48.19-99.47) & 61.54 & (40.04-94.58) & 13 & 69.8 & $(56.02-86.96)$ & 68.08 & $(54.17-85.57)$ \\
\hline 2010-2015 & 33 & 81.38 & $(68.98-96.02)$ & 72.66 & (57.68-91.51) & 33 & 81.2 & $(68.9-95.7)$ & 70.31 & (54.71-90.36) \\
\hline \multicolumn{11}{|l|}{ GEOGRAPHICAL AREA } \\
\hline Alt Empordà Coast & 8 & 62.5 & $(36.54-100)$ & 46.88 & $(21.49-100)$ & 8 & 63.07 & (38.45-103.46) & 48.1 & $(24.06-96.17)$ \\
\hline Alt Empordà Interior & 20 & 79.69 & (63.73-99.63) & 67.61 & (49.04-93.22) & 20 & 73.82 & $(56.89-95.8)$ & 59.81 & (42.09-84.98) \\
\hline Baix Empordà & 1 & 100 & $(100-100)$ & 100 & $(100-100)$ & 1 & 100 & $(100-100)$ & 100 & $(100-100)$ \\
\hline Cerdanya & 5 & 80 & $(51.61-100)$ & 60 & $(29.33-100)$ & 5 & 80.32 & $(54.1-119.23)$ & 62.04 & $(33.12-116.23)$ \\
\hline Garrotxa & 15 & 80 & $(62.12-100)$ & 54 & $(32.22-90.51)$ & 15 & 78.89 & $(64.45-96.56)$ & 63.59 & $(48.16-83.97)$ \\
\hline Gironès & 4 & 50 & $(18.77-100)$ & 25 & $(4.58-100)$ & 4 & 50.02 & $(22.1-113.22)$ & 25.07 & $(7-89.75)$ \\
\hline Pla De L'estany & 4 & 50 & $(18.77-100)$ & 50 & $(18.77-100)$ & 4 & 52.94 & $(23.63-118.62)$ & 58.18 & $(25.97-130.34)$ \\
\hline Ripollès & 5 & 80 & $(51.61-100)$ & 80 & $(51.61-100)$ & 5 & 80.84 & $(54.53-119.86)$ & 82.27 & (55.49-121.98) \\
\hline Selva Coast & 3 & 66.67 & (29.95-100) & 66.67 & (29.95-100) & 3 & 66.88 & (34.83-128.44) & 68.59 & $(35.72-131.71)$ \\
\hline Selva Interior & 8 & 62.5 & (36.54-100) & 46.88 & (21.49-100) & 8 & 63.07 & (38.45-103.46) & 48.1 & $(24.06-96.17)$ \\
\hline TOTAL & 65 & 73.6 & $(63.57-85.21)$ & 58.69 & $(47.28-72.84)$ & 65 & 70.28 & $(58.67-84.19)$ & 61.45 & (47.47-79.55) \\
\hline
\end{tabular}




\section{Discussion}

We present the first registry-based data on trends in PC incidence and survival rates in Spain for all histological types, including neuroendocrine tumors.

Our results for the Girona province revealed an upward trend in PC incidence throughout the study period regardless of sex, age, tumour location, stage, period of diagnosis and geographical area. In contrast with Wood et al. [7] who reported a stable or even decreasing trend, our findings concur with recent publications that report a stepwise increase of PC incidence in the last decades, especially evident in developed countries [4,6,17-20]. According to the prevailing worldwide tendency [4], in the current study PC incidence is higher in men than in females and increases with age for both sexes, with $70 \%$ of patients being older than 64 years at diagnosis. The aging and longevity of the population, the increasing incidence of obesity and adult-onset diabetes, and exposure to risk factors such as smoking, and some dietary habits (consumption of red and processed meat or excessive alcohol intake, for example) may partially account for the present findings [21].

In our series we found $51.5 \%$ of PC without microscopic verification, a higher result than the proportion published in other studies [17]. Obtaining tissue for diagnosis can be notoriously difficult in patients with suspected PC and it often requires invasive methods, such as ultrasound-guided biopsies or even surgery. These procedures can be challenging in elderly patients or in those with poor performance status, reason whereby we believe there is a high proportion of PC with unspecified histology (malignant neoplasm) in our series. This weakness in registry-based studies of PC has been largely reported. In EUROCARE-4 [22], a study that collected data from 93 European cancer registries between 1995 and 2002, the microscopic verification rate was 63\% (range 30-91\%) for PC. What stands out from our data is the ASR behaviour of the non-HC PC, whose incidence rate gradually decreases with an EAPC of -2.23. These findings not only reflect the introduction and growing use of modern diagnostic techniques in our daily clinical practice, but also a change of attitude towards pancreatic cancer leaving nihilism behind.

There is growing evidence supporting an association between adult weight gain, childhood or adolescent obesity, and increased risk of colorectal, endometrial, and pancreatic cancers [23]. Sung et al. have recently reported an increasing of PC incidence in young adults compared to $>45$-year-old population, and linked it to excess bodyweight, obesity-related health conditions and lifestyle factors [24]. Unlike them, although in our study PC incidence is growing in all age groups, we found a greater rise of incidence trend in older people ( $\geq 55$ years old) compared with younger adults ( $<55$ years old), and the difference was more evident when we limited our analysis to non-PNET histologically confirmed cases. This could be explained by two main reasons: first, the low number of cases diagnosed $<45$ years old $(n=52)$; and, second, although in Spain obesity rates in adolescents and young adults are rising due to changes in life-style and diet [25], it is a recent issue and it is not reflected yet in the PC incidence rates during the study period.

In accordance with previously reported data $[5,11,26]$, most cases $(n=613)$ were diagnosed in stage IV $(67.69 \%)$. This data reflects the absence of specific symptoms in the early stages of pancreatic tumors. Even in the highest income countries most PC patients are diagnosed with metastatic or locally advanced disease [27], a fact which determines the poor survival of PC patients worldwide.

Survival for PC, as reported in the EUROCARE-5 study [10], is particularly low: European average RS is $26 \%$ at one year and $7 \%$ at five years since diagnosis, similar to what we found in our series (Figure 3). In accordance with previously published data [8], survival decreased with advancing age in our study, except for PNETs, where we found no differences among age groups.

We observed better survival in males than in females, and this is a previously unreported finding. In Europe, 5-year RS was similar in both sexes when considering European regions or countries [10]. Looking back to the demographic characteristics of our population (Table 1), two important data stand out: the median age of the female cohort is higher than the males' $(75 \mathrm{y} \mathrm{vs.} 70 \mathrm{y})$ and the main difference lies in the proportion of population over $75 \mathrm{y}$ at time of PC diagnosis (34\% of males and 
$53 \%$ of females). As age is one of the strongest prognostic factors for PC, this may explain the poor outcomes of females in our study.

As expected, due to the different etiology and biology of the PNET neoplasms [28,29], survival was much higher than for the rest of the study population (the non-PNETs). The 5-year RS for this subgroup was 61.45 (95\% CI 47.47; 79.55), above those observed in Europe for the period 2000-2007: $42.9 \%(95 \%$ CI $41.0 ; 44.8)$ [30]. Following the whole series tendency, it improved thorough the study timeframe. When we approach PNETs' survival results, it is to note that since 2010, the international recommendation for the registration of PNET in cancer registries has changed. The new stage classification of NETs is based on histological grades, thus since its implementation all NETs should be registered, whereas until then only invasive cases were registered. In Girona all cases were recoded following these recommendations, and due to this fact, PNETs survival may have improved. Unlike in the rest of PC, females presented better survival than males, and survival was similar among the age groups studied.

With regards to survival rates in non-PNETs, irrespective of being microscopically confirmed or not, encouraging progress in survival over time was detected. We did not only find an increase in 1-year RS, but also, in contrast with the published data from the UK [31] and the Canadian Cancer Registry [32], an upswing in the 5-year RS from $1.06 \%(95 \%$ CI $0.36 ; 3.1)$ in the initial lustrum (1994-1998) to $7.76 \%(95 \%$ CI 5.22; 11.53) in the last time period of the study (2010-2015). We have an ongoing higher resolution study in order to analyze the treatment regimens received by this population and their impact on survival.

\section{Strengths and Weaknesses}

Strengths of this study include the use of real-world data from a high-quality population-based Cancer Registry, the large sample size, and the long-term and virtually complete follow-up of the population that yield robust survival. However, the study presents some limitations that should be kept in mind when interpreting our results: first the territory-linked data as a result of being the Regional Cancer Registry as our source of information. Second, we had missing information on clinical variables such as AJCC (American Joint Committee on Cancer) stage and tumour location for more than half of the study population. And third, we lacked information on tumour histology in $51 \%$ of patients.

\subsection{Conclusions}

We present a large, comprehensive, and up-to-date analysis of incidence and survival data of all PC in Girona (Spain) obtained from a high-quality cancer registration system. To the authors' knowledge, this is the first population-based study in Spain to analyse both incidence and survival trends for PC. Our results revealed an upward trend in PC incidence throughout the study period regardless of sex, age, tumour location, stage, period of diagnosis and geographical area, as well as an encouraging increase in survival in recent years. PNETs diagnosis had the best survival rates. Among non-PNETs or non-HC PC, advanced age and stage were associated with poorer survival rates. This information will contribute to estimate the burden of PC in Spain and will serve as a baseline for future analysis, allowing comparison with other registries' data.

Supplementary Materials: The following are available online at http://www.mdpi.com/1660-4601/17/24/9538/s1, Figure S1: Observed survival curves (\%) up to 5 years after diagnosis. Table S1: Frequency of the histological groupings based on the classification of pancreatic tumours of the 4th edition of WHO classification of tumours of the digestive system. Histologies present in our study that are not found on the classification are included in the table. Table S2: Pancreatic cancer rates for each individual year (1994-2015); total incidence of pancreatic cancer in the province of Girona during the period 1994-2015. Table S3: Pancreatic cancer rates for each individual year (1994-2015). Incidence of pancreatic cancer in men in the province of Girona during the period 1994-2015. Table S4: Pancreatic cancer rates for each individual year (1994-2015); Incidence of pancreatic cancer in women in the province of Girona during the period 1994-2015. 
Author Contributions: Conceptualization, A.G.-V. and R.M.-G.; methodology, R.M.-G.; software L.Z.-P.; validation, M.C.C.-G., W.C., and R.G.; formal analysis L.Z.-P.; investigation, H.T., M.V., R.L.; resources, M.P.; data curation, M.P. and R.L.; writing — original draft preparation, A.G.-V.; writing—review and editing, N.M. and E.D.; supervision, A.G.-V. and R.M.-G.; project administration, R.M.-G.; All authors have read and agreed to the published version of the manuscript.

Funding: This research received no external funding.

Acknowledgments: We acknowledge the Girona Cancer Registry and the Catalan Institute of Oncology in Girona for their administrative and technical support.

Conflicts of Interest: The authors declare that there are no conflicts of interest regarding the publication of this article.

\begin{tabular}{ll}
\multicolumn{2}{l}{ Abbreviations } \\
PC & Pancreatic cancers \\
PNETS & Pancreatic neuroendocrine tumours \\
Non PNETs & Pancreatic carcinomas non-neuroendocrine \\
Non-HC PC & Pancreatic cancers non-histologically confirmed \\
ASR & Age-standardized rate \\
EAPC & Estimated annual percentage change \\
CR & Crude rate \\
RS & Relative survival \\
GWAS & Genome-wide association study
\end{tabular}

\section{References}

1. Maisonneuve, P. Epidemiology and burden of pancreatic cancer. Presse Med. 2019, 48, e113-e123. [CrossRef] [PubMed]

2. Ferlay, J.; Colombet, M.; Soerjomataram, I.; Dyba, T.; Randi, G.; Bettio, M.; Gavin, A.; Visser, O.; Bray, F. Cancer incidence and mortality patterns in Europe: Estimates for 40 countries and 25 major cancers in 2018. Eur. J. Cancer 2018, 103, 356-387. [CrossRef] [PubMed]

3. Bray, F.; Ferlay, J.; Soerjomataram, I.; Siegel, R.L.; Torre, L.A.; Jemal, A. Global cancer statistics 2018: GLOBOCAN estimates of incidence and mortality worldwide for 36 cancers in 185 countries. CA Cancer J. Clin. 2018, 68, 394-424. [CrossRef] [PubMed]

4. Red Española de Registros de Cáncer (REDECAN). Estimaciones de la Incidencia del Cáncer en España, 2020. Red Española de Registros de Cáncer (REDECAN). 2020. Available online: http://redecan.org/es/index.cfm (accessed on 21 April 2020).

5. Carrato, A.; Falcone, A.; Ducreux, M.; Valle, J.W.; Parnaby, A.; Djazouli, K.; Alnwick-Allu, K.; Hutchings, A.; Palaska, C.; Parthenaki, I. A Systematic Review of the Burden of Pancreatic Cancer in Europe: Real-World Impact on Survival, Quality of Life and Costs. J. Gastrointest. Cancer 2015, 46, 201-211. [CrossRef]

6. Rawla, P.; Sunkara, T.; Gaduputi, V. Epidemiology of Pancreatic Cancer: Global Trends, Etiology and Risk Factors. World J. Oncol. 2019, 10, 10-27. [CrossRef]

7. NIH National Cancer Institute. Pancreatic Cancer-Cancer Stat Facts. Available online: https:/seer.cancer. gov/statfacts/html/pancreas.html (accessed on 11 May 2019).

8. Lepage, C.; Capocaccia, R.; Hackl, M.; Lemmens, V.; Molina, E.; Pierannunzio, D.; Sant, M.; Trama, A.; Faivre, J.; Zielonke, N.; et al. Survival in patients with primary liver cancer, gallbladder and extrahepatic biliary tract cancer and pancreatic cancer in Europe 1999-2007: Results of EUROCARE-5. Eur. J. Cancer 2015, 51, 2169-2178. [CrossRef]

9. Chirlaque, M.-D.; Salmerón, D.; Galceran, J.; Ameijide, A.; Mateos, A.; Torrella, A.; Jiménez, R.; Larrañaga, N.; Marcos-Gragera, R.; Ardanaz, E.; et al. Cancer survival in adult patients in Spain. Results from nine population-based cancer registries. Clin. Transl. Oncol. 2018, 20, 201-211. [CrossRef]

10. De Angelis, R.; Sant, M.; Coleman, M.P.; Francisci, S.; Baili, P.; Pierannunzio, D.; Trama, A.; Visser, O.; Brenner, H.; Adarnaz, E.; et al. Cancer survival in Europe 1999-2007 by country and age: Results of EUROCARE-5-a population-based study. Lancet Oncol. 2014, 15, 23-34. [CrossRef] 
11. Ryan, D.P.; Hong, T.S.; Bardeesy, N. Pancreatic Adenocarcinoma. N. Engl. J. Med. 2014, 371, $1039-1049$. [CrossRef]

12. Fritz, A.; Percy, C.; Jack, A.; Shanmugaratnam, K.; Sobin, L.; Parkin, D.M.W.S. International Classification of Diseases for Oncology (ICD-O)-3rd Edition, 1st Revision; World Health Organization: Geneva, Switzerland, 2000.

13. Bosman, F.T.; Carneiro, F.; Hruban, R.H.; Theise, N.D. (Eds.) WHO Classification of Tumours of the Digestive System, 4th ed.; International Agency for Research on Cancer: Lyon, France, 2010.

14. Clèries, R.; Ameijide, A.; Buxó, M.; Vilardell, M.; Martínez, J.M.; Alarcón, F.; Cordero, D.; Díez-Villanueva, A.; Yasui, Y.; Marcos-Gragera, R.; et al. WebSurvCa: Estimación vía web de las probabilidades de fallecimiento y de supervivencia de una cohorte. Gac. Sanit. 2018, 32, 492-495. [CrossRef]

15. Perme, M.P.; Stare, J.; Estève, J. On estimation in relative survival. Biometrics 2012, 68, 113-120. [CrossRef] [PubMed]

16. Dickman, P.W.; Coviello, E. Estimating and modeling relative survival. Stata J. 2015, 15, 186-215. [CrossRef]

17. Huang, L.; Jansen, L.; Balavarca, Y.; Babaei, M.; Van Der Geest, L.G.M.; Lemmens, V.; Van Eycken, L.; De Schutter, H.; Johannesen, T.B.; Žakelj, M.P.; et al. Stratified survival of resected and overall pancreatic cancer patients in Europe and the USA in the early twenty-first century: A large, international population-based study. BMC Med. 2018, 16, 125. [CrossRef] [PubMed]

18. Crocetti, E.; Mancini, S. Pancreatic cancer incidence rises also in Italy. Int. J. Epidemiol. 2017, 46, 2090. [CrossRef]

19. Bouvier, A.-M.; Uhry, Z.; Jooste, V.; Drouillard, A.; Remontet, L.; Launoy, G.; Leone, N.; French Network of Cancer Registries (Francim). Focus on an unusual rise in pancreatic cancer incidence in France. Int. J. Epidemiol. 2017, 46, 1764-1772. [CrossRef]

20. Vajdic, C.M.; Laaksonen, M.A. Commentary: Unusual pancreatic cancer incidence and mortality patterns. Int. J. Epidemiol. 2017, 46, 1772-1773. [CrossRef]

21. Food, Nutrition, Physical Activity, and the Prevention of Pancreatic Cancer. Continuous Update Project Report: World Cancer Research Fund/American Institute for Cancer Research. 2018. Available online: https://www.wcrf.org/dietandcancer (accessed on 10 May 2020).

22. De Angelis, R.; Francisci, S.; Baili, P.; Marchesi, F.; Roazzi, P.; Belot, A.; Crocetti, E.; Pury, P.; Knijn, A.; Coleman, M.; et al. The EUROCARE-4 database on cancer survival in Europe: Data standardisation, quality control and methods of statistical analysis. Eur. J. Cancer 2009, 45, 909-930. [CrossRef]

23. Sung, H.; Siegel, R.L.; Torre, L.A.; Pearson-Stuttard, J.; Islami, F.; Fedewa, S.A.; Sauer, A.G.; Shuval, K.; Gapstur, S.M.; Jacobs, E.J.; et al. Global patterns in excess body weight and the associated cancer burden. CA Cancer J. Clin. 2019, 69, 88-112. [CrossRef]

24. Sung, H.; Siegel, R.L.; Rosenberg, P.S.; Jemal, A. Emerging cancer trends among young adults in the USA: Analysis of a population-based cancer registry. Lancet Public Health 2019, 4, e137-e147. [CrossRef]

25. Aranceta-Bartrina, J.; Serra-Majem, L.; Foz-Salac, M.; Moreno-Esteban, B. Grupo Colaborativo SEEDO. Prevalencia de obesidad en España. Med. Clin. (Barc.) 2005, 125, 460-466. [CrossRef]

26. Hidalgo, M.; Cascinu, S.S.; Kleeff, J.J.; Labianca, R.; Löhr, J.M.J.; Neoptolemos, J.; Real, F.F.; Van Laethem, J.-L.; Heinemann, V. Addressing the challenges of pancreatic cancer: Future directions for improving outcomes. Pancreatology 2015, 15, 8-18. [CrossRef] [PubMed]

27. Arnold, M.; Rutherford, M.J.; Bardot, A.; Ferlay, J.; Andersson, T.M.-L.; Myklebust, T.Å.; Tervonen, H.; Thursfield, V.; Ransom, D.; Shack, L.; et al. Progress in cancer survival, mortality, and incidence in seven high-income countries 1995-2014 (ICBP SURVMARK-2): A population-based study. Lancet Oncol. 2019, 20, 1493-1505. [CrossRef]

28. Gatta, G.; Capocaccia, R.; Botta, L.; Mallone, S.; De Angelis, R.; Ardanaz, E.; Comber, H.; Dimitrova, N.; Leinonen, M.K.; Siesling, S.; et al. Burden and centralised treatment in Europe of rare tumours: Results of RARECAREnet-a population-based study. Lancet Oncol. 2017, 18, 1022-1039. [CrossRef]

29. Halfdanarson, T.R.; Rabe, K.G.; Rubin, J.; Petersen, G.M. Pancreatic neuroendocrine tumors (PNETs): Incidence, prognosis and recent trend toward improved survival. Ann. Oncol. 2008, 19, 1727-1733. [CrossRef]

30. Lykoudis, P.M.; Partelli, S.; Muffatti, F.; Caplin, M.E.; Falconi, M.; Fusai, G.K.; Hackl, M.; Van Eycken, E.; Henau, K.; Dimitrova, N.; et al. Treatment challenges in and outside a specialist network setting: Pancreatic neuroendocrine tumours. Eur. J. Surg. Oncol. 2019, 45, 46-51. [CrossRef] 
31. Cancer Research UK. 2020. Available online: https://www.cancerresearchuk.org/health-professional/cancerstatistics/statistics-by-cancer-type/pancreatic-cancer (accessed on 29 April 2020).

32. Akhtar-Danesh, G.G.; Finley, C.; Akhtar-Danesh, N. Long-term trends in the incidence and relative survival of pancreatic cancer in Canada: A population-based study. Pancreatology 2016, 16, 259-265. [CrossRef]

Publisher's Note: MDPI stays neutral with regard to jurisdictional claims in published maps and institutional affiliations.

(C) 2020 by the authors. Licensee MDPI, Basel, Switzerland. This article is an open access article distributed under the terms and conditions of the Creative Commons Attribution (CC BY) license (http://creativecommons.org/licenses/by/4.0/). 